○ Open Access Full Text Article

REVIEW

\title{
Interventional NIR Fluorescence Imaging of Cancer: Review on Next Generation of Dye-Loaded Protein-Based Nanoparticles for Real-Time Feedback During Cancer Surgery
}

This article was published in the following Dove Press journal:

International Journal of Nanomedicine

\author{
Raluca Borlan ${ }^{1,2}$ \\ Monica Focsan ${ }^{2}$ \\ Dana Maniu' \\ Simion Astilean ${ }^{1,2}$ \\ 'Biomolecular Physics Department, \\ Faculty of Physics, Babeș-Bolyai \\ University, Cluj-Napoca, Cluj, Romania; \\ ${ }^{2}$ Nanobiophotonics and Laser \\ Microspectroscopy Centre, \\ Interdisciplinary Research Institute in \\ Bio-Nano-Sciences, Babeș-Bolyai \\ University, Cluj-Napoca, Cluj, Romania
}

Correspondence: Simion Astilean Email simion.astilean@ubbcluj.ro

Monica Focsan

Email monica.iosin@ubbcluj.ro

\begin{abstract}
The use of fluorescence imaging technique for visualization, resection and treatment of cancerous tissue, attained plenty of interest once the promise of whole body and deep tissue near-infrared (NIR) imaging emerged. Why is NIR so desired? Contrast agents with optical properties in the NIR spectral range offer an upgrade for the diagnosis and treatment of cancer, by dint of the deep tissue penetration of light in the NIR region of the electromagnetic spectrum, also known as the optical window in biological tissue. Thus, the development of a new generation of NIR emitting and absorbing contrast agents able to overcome the shortcomings of the basic free dye administration is absolutely essential. Several examples of nanoparticles (NPs) have been successfully implemented as carriers for NIR dye molecules to the tumour site owing to their prolonged blood circulation time and enhanced accumulation within the tumour, as well as their increased fluorescence signal relative to free fluorophore emission and active targeting of cancerous cells. Due to their versatile structure, good biocompatibility and capability to efficiently load dyes and bioconjugate with diverse cancer-targeting ligands, the research area of developing protein-based NPs encapsulated or conjugated with NIR dyes is highly promising but still in its infancy. The current review aims to provide an up-to-date overview on the biocompatibility, specific targeting and versatility offered by protein-based NPs loaded with different classes of NIR dyes as next-generation fluorescent agents. Moreover, this study brings to light the newest and most relevant advances involving the state-of-the-art NIR fluorescent agents for the realtime interventional NIR fluorescence imaging of cancer in clinical trials.
\end{abstract}

Keywords: clinical translation, fluorescent contrast agents, organic nanoparticles, nearinfrared dyes

\section{Introduction}

Worldwide, cancer is the second leading cause of death, reaching by 2018 the appalling total of 9.6 million deaths. ${ }^{1}$ Prevalence of cancer and mortality are rising due to several complex reasons, the basic roots being the aging and growth of the population, together with risk factors related to social and economic development. ${ }^{2}$ The International Agency for Research on Cancer estimated in 2018 that 1 in 5 men and 1 in 6 women develop cancer during their lifespan, while 1 in 8 men and 1 in 11 women unfortunately die of cancer. Although prodigious amounts of research were conducted over the past century to improve the current treatment options of cancer, 
no genuine changes were made to the sine qua non of treatment for tumours, namely surgery. ${ }^{3}$ Wistfully, none of the different imaging modalities used for tumour detection and surgical planning in a preoperative setting, eg computed tomography, positron emission tomography, singlephoton emission computed tomography, planar scintigraphy, magnetic resonance imaging, can be translated in the operating theatre due to poor tissue manipulation and mismatched patient position. ${ }^{4-6}$ Moreover, despite the high resolution attained in whole-body imaging, computed tomography has limited specificity in regards to detection of small lesions, less than $10 \mathrm{~mm}$, and the use of ionising radiation must be carried out following strict standard procedures, to avoid the endangerment of surgeons and nurses. $^{7,8}$ Thus, although the high-resolution eyes (50 $\mu \mathrm{m}^{8}$ ) and hands of the surgeon can easily distinguish anatomical structures, during resection it is challenging to differentiate between healthy tissue and malignant lesions ending in the undesired removal of healthy tissue (poor functional outcomes) or an incomplete resection (local recurrence). After surgery, it can take up to 7 days for the pathology report to be sent to the doctor and in the unfortunate event of positive margins, a reintervention is not recommended, the patient being in recovery. ${ }^{3,8}$ Thus, a new strategy to detect tumours and concomitantly give a real-time feedback during surgery is needed in order to suppress this disease. ${ }^{5}$

Set side-by-side with the classical imaging techniques described above, fluorescence imaging modalities offer high-resolution images, capable of discerning lesions even smaller than $10 \mu \mathrm{m}$. The phenomenon of fluorescence is dependent on the nature of the excited state of a molecule or substance, thus when in an excited singlet state (eg after absorption of a photon at a certain wavelength), by pairing the electron in the excited orbital of opposite spin, to a second electron in the ground state orbital, the return to the ground state occurs rapidly, by the emission of a photon at longer wavelengths. ${ }^{9}$ In medicine, fluorescence imaging is a widely used imaging technique for the detection of photons emitted from diseased tissue, after administration of diverse contrast agents of interest. Due to the relatively low costs and flexibility, fluorescence imaging methods are currently being investigated for translation to the operating room, thus improving the resection outcomes and patient lifestyle. ${ }^{3,8}$ Figure 1 depicts the schematic representation of a surgical field set up for cancer patients, injected with a fluorescent agent prior to the surgery, and the fluorescence imaging system
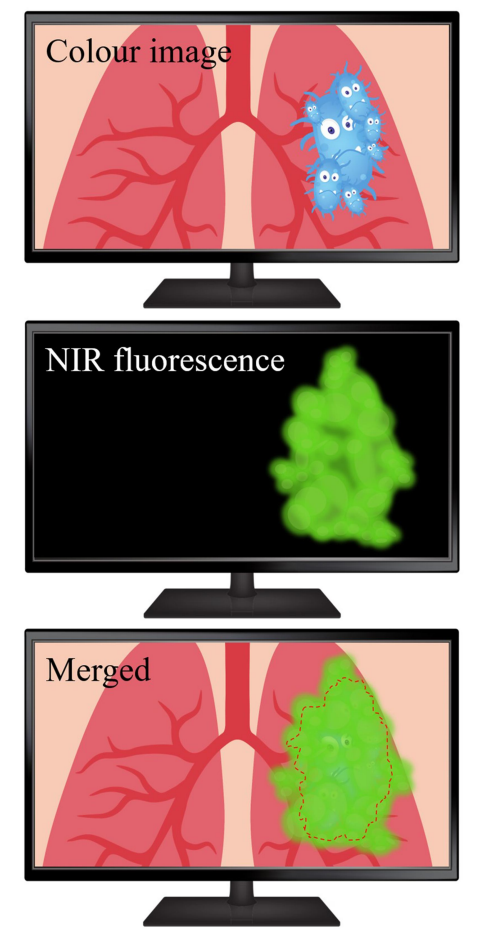

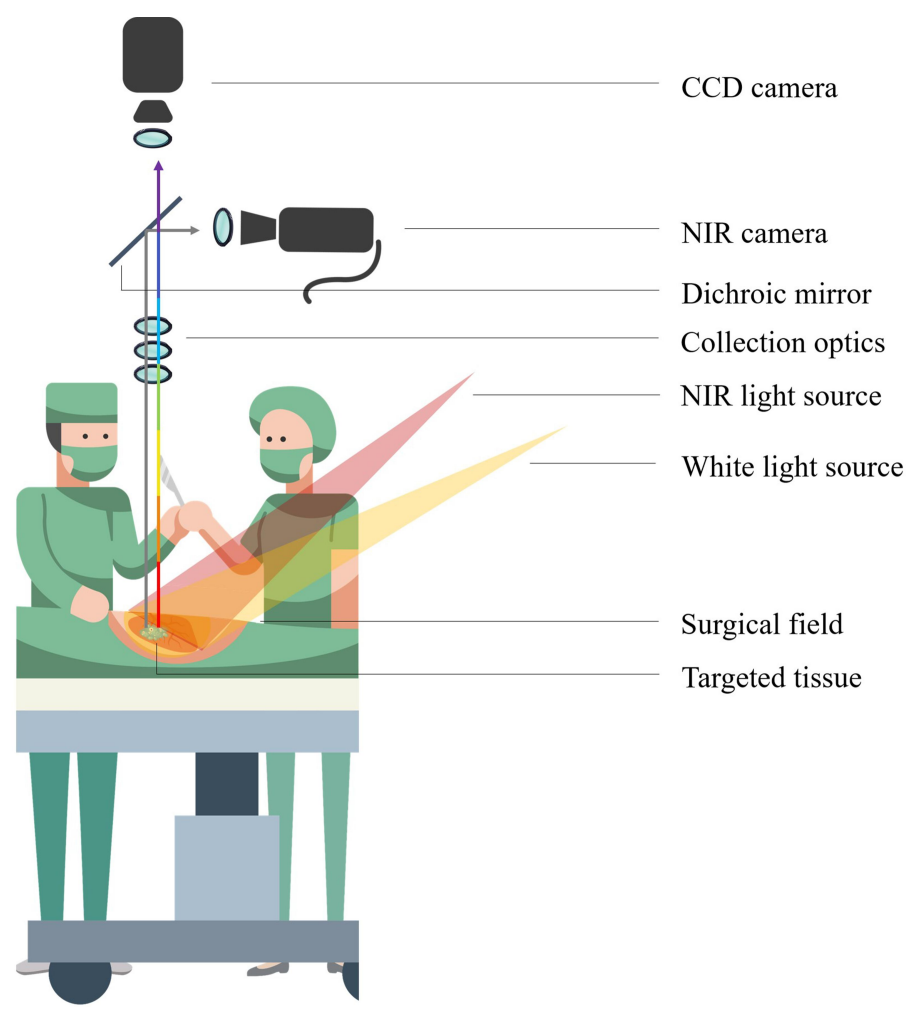

Figure I Schematic representation of the surgical field and NIR fluorescence imaging system able to capture in real-time two imaging channels simultaneously. 
able to capture in real-time two imaging channels simultaneously; during the surgery, the overlaid image of the two imaging channels is displayed, offering an improved visualisation and detection of malignant tissue. The main disadvantage of visible light fluorescence imaging (eg low tissue penetration and light absorbance by tissue and blood) can be overcome by employing contrast agents in the NIR region of the electromagnetic spectrum. ${ }^{5}$ To outdo the harsh side effects, low photostability and non-specific targeting of standard free dye administration, a multitude of types of NPs have been developed to aptly encapsulate and deliver dyes to the desired type of cancer cells. Among them, protein-based NPs exhibit special interests as they are biodegradable, biocompatible and have a versatile structure. ${ }^{10,11}$

In this review, we bring to light the recent advancements towards the clinical translation of dye-loaded protein-based NPs as fluorescent agents for the in situ NIR image-guided detection and resection of cancerous tissue. We also aim to provide an up-to-date overview on the biocompatibility, specific targeting and versatility offered by NIR dye loaded protein-based NPs as the next generation of anti-cancer agents and a summarization of the newest and most relevant clinical trials in real-time interventional NIR fluorescence imaging of cancer using stateof-the-art NIR fluorescent agents.

\section{Near-Infrared Dyes Selected for Fluorescence Imaging}

The use of dyes that both absorb and emit light in the red and NIR region of the spectrum was the stepping stone to overcome the main drawbacks (eg the absorption by tissue and blood and scattering of light, autofluorescence of tissue) that limited fluorescence imaging in the UV-Vis region to the qualitative surface imaging of only single cell and thin tissue layers. While proteins, melanin, haemoglobin and water have high absorbance coefficients over almost the entire UVVis spectrum $200-650 \mathrm{~nm},{ }^{12}$ and collagen absorbs at wavelengths over $1450 \mathrm{~nm},{ }^{12}$ the tissue penetration of light is highest (up to $2 \mathrm{~cm}^{8}$ ) in the $650-1450 \mathrm{~nm}$ range of the electromagnetic spectrum, also known as the optical window in biological tissue. Hence, in the past years, NIR fluorescence imaging and employing NIR fluorophores in preclinical research gained mass attention globally., ${ }^{5,12}$ Until today, while fluorophores with emission in a wide range of the electromagnetic spectrum have been approved by the Food and Drug Administration (FDA) for medical purpose, only two emit light in the NIR region 650-900 nm, namely Indocyanine Green (ICG) and Methylene Blue (MB). ${ }^{13,14}$ Unlike classic small-molecule fluorophores, via the process of restriction of intramolecular motion, aggregation-induced emission luminogens can emit bright NIR light in aggregated states. ${ }^{15,16}$ Thanks to their strong NIR fluorescence and good photobleaching resistance, aggregation-induced emission luminogens recently attained great interest in biomedical applications. ${ }^{17,18}$

Notwithstanding, organic dyes are still the first option as NIR contrast agents for biomedical imaging, and most of them can be catalogued as squaraines, BODIPY, porphyrins, phthalocyanines or cyanines. ${ }^{12,19}$ Squaraine (squarylium dyes) molecules contain an oxocyclobutenolate core with electron-donating substituents (aromatic or heterocyclic components) at both ends. Squaraines present excellent quantum yields, high absorption coefficients and good photoconductivity, although no significant progress was made in improving water solubility since their first reported synthesis in 1965 by Treibs and Jacob. ${ }^{20-22}$

BODIPY (4,4-difluoro-4-bora-3a,4a-diaza-s-indacene borondipyrromethene dye) were synthesized for the first time in 1968 by (the same) Treibs and Kreuze, and consist of two pyrrole rings linked by a methine bridge, and complexed with a difluoroboron center. Thanks to their good photochemical and thermal stability and excellent quantum yield, the use of BODIPY dyes can be appealing for a wide area of application, such as fluorescent switches, molecular photonic wires or laser dyes; but, despite the numerous attempts in shifting their absorption and emission spectrum to the optical window (NIR region) and as a consequence of their poor water solubility, most of BODIPY dyes are not suited for in vivo fluorescence imaging. ${ }^{12,20,21}$

Even though the innovative capacity of porphyrin dyes was only upheld later on in history, Hippocrates was the first to notice the negative effect of excess porphyrins in humans. Structurally, porphyrins are a category of aromatic macrocycle organic compounds consisting of four pyrrole subunits linked to each other by methine groups and exist by nature in species, such as heme, cytochromes and chlorophylls. Undeterred by the poor quantum yields and low absorption in the NIR region of simple porphyrins, a small number of more complex porphyrin derivatives were synthesized, displaying promising optical properties for in vivo imaging in the red and NIR region of the spectrum. In addition to their wide applications as a dye, porphyrins are also ideal for molecular materials that can be used in biomedicine, electronics and optoelectronics. ${ }^{20,21,23,24}$ 
Phthalocyanines are a group of synthetic dyes containing four isoindole units interconnected by nitrogen atoms, so they form a large ring consisting of $18 \pi$ electrons. These aromatic macrocycle porphyrin derivatives were originally synthesized by happenstance in 1928, but their efficacy as dyes and pigments was established by Linstead in 1934. Owing to their high photostability and good thermal and chemical stability, phthalocyanines have been widely used in fields associated with laser recording materials, chemical sensors, intrinsic semiconductors and are extensively investigated as photoactive chemical compounds in photodynamic therapy. However, phthalocyanines have been overlooked for in vivo imaging considering their poor water solubility, predilection to aggregate and the fact that only a few of them exhibit absorption and emission properties within the optical window in biological tissue. ${ }^{19,21,25,26}$

The governing fluorophores and gold standard (ICG) of successful in vivo applications continue to belong to the popular family of cyanines (polymethine cyanine dyes) and are defined by two nitrogen atoms connected to each other by a polymethine bridge composed of an odd number of methine units, while each nitrogen atom is contained within an aromatic heterocyclic unit (eg benzoxazole, benzothiazole, indole). The first cyanine dye ever synthesized was described as a blue solid by Williams in 1856 and, since then, these dyes have been used in a broad range of applications from paints to medicinal purposes. Of late, a new generation of cyanine dyes distinguishes by their native tumour targeting capabilities together with good in vivo imaging outcomes, which are heptamethine dyes. On account of their lipophilic cationic nature heptamethine dyes preferentially accumulate in the mitochondria of cancerous cells, giving a great signalto-noise ratio in tumours compared to healthy tissue sites. $^{20,21,27}$ Table 1 presents the chemical structures and photophysical features of archetypal far-red and NIR fluorophores.

To surmount the shortcomings of administrating free dyes, eg hydrophobicity, aggregation, poor quantum yield and low photostability, an up-and-coming approach is the efficient encapsulation or conjugation of the fluorescent agents (Figure 2) with diverse NPs. ${ }^{19,28}$

\section{Dye-Loaded Protein-Based Nanoparticles for Interventional NIR Imaging of Cancer - Preclinical Studies}

Over the past years, researchers delved into the implementation of NPs as personalized contrast agents for medical imaging, owing to their ability to efficiently load and thus overcome the drawback of using free NIR imaging agents, which predominantly present low photostability, great tendency to aggregate and poor solubility in aqueous solutions. ${ }^{11,29}$ Furthermore, some NPs with diameters in the optimal size range can cross the blood-brain barrier with ease ${ }^{11}$ and have the capability to accumulate preferentially within tumour microenvironments, either through passive targeting mediated by the enhanced permeability and retention (EPR) effect or via active targeting by bioconjugation with cancer-specific ligands. ${ }^{11,30}$ On the other hand, in spite of the considerable amount of research carried out for a better understanding of the interplay between synthetic NPs and biological systems, merely a narrow percentage, $2 \%$, reached clinical translation. ${ }^{10}$ Thus, an appealing alternative to synthetic NPs is the employment of the versatile, nontoxic and biodegradable protein-based NPs loaded with NIR fluorophores as medical imaging agents. ${ }^{10,29}$

To date, diverse proteins with plant-based origins (eg gliadin, ${ }^{31-33}$ legumin, ${ }^{34}$ zein $^{35-37}$ ), animal-based origins (eg gelatin, ${ }^{38-42}$ silk, ${ }^{43-46}$ casein, ${ }^{47-49}$ whey, ${ }^{50}$ multimeric enzymes, ${ }^{51-53}$ ferritin, ${ }^{54-57}$ transferrin, ${ }^{58-62}$ albumin ${ }^{63-67}$ ) and even virus-derived proteins ${ }^{68-72}$ have been widely used as prime materials for the development of NPs with emerging applications in medicine, but nearly half of them prevail to be studied as NIR fluorescence imaging agents (Figure 3).

The main advantage of NPs synthesized using vegetal proteins over animal-based proteins is probably the low cost of production. ${ }^{11}$ Zein is a major component of the total protein in corn kernels, ${ }^{35}$ with a molecular weight of 22-27 $\mathrm{kDa}^{73}$ Zein proteins have an amphiphilic character $^{37}$ showing good solubility in alcohol but not in water, ${ }^{35}$ and are highly used as edible coatings in the food industry. ${ }^{36}$ Moreover, zein is classified by FDA as a generally regarded as safe (GRAS) excipient for the coating of pills and other pharmaceuticals. ${ }^{73}$ Thanks to their biodegradability and nontoxic properties, the implementation of zein-based NPs as delivery agents for the control release of anticancer drugs presents promising 
Table I Far-Red and NIR Dyes and Their Photophysical Properties

\begin{tabular}{|c|c|c|c|c|}
\hline $\begin{array}{l}\text { Fluorophore } \\
\text { Class }\end{array}$ & $\begin{array}{l}\text { NIR } \\
\text { Fluorophore }\end{array}$ & Chemical Structure & Photophysical Features & Ref. \\
\hline Squaraine & $\begin{array}{l}\text { lodine-substituted } \\
\text { squaraine }\end{array}$ & & $\begin{array}{l}\lambda_{\text {abs }}[\mathrm{nm}]: 699 \varepsilon\left[\mathrm{M}^{-1} \mathrm{~cm}^{-1}\right]: 221,000 \lambda_{\mathrm{em}}[\mathrm{nm}]: 713 \\
\Phi[\%]: 58 \text { In dimethylsulfoxide }\end{array}$ & {$[26,126]$} \\
\hline BODIPY & $\begin{array}{l}\text { BODIPY-based ion } \\
\text { sensor }\end{array}$ & & $\begin{array}{l}\lambda_{\text {abs }}[\mathrm{nm}]: 600 \lambda_{\mathrm{em}}[\mathrm{nm}]: 656 \Phi[\%]: 12 \mathrm{ln} \text { tris } \\
\text { hydrochloride }\end{array}$ & {$[127,128]$} \\
\hline Porphyrin & Chlorin e6 & & $\begin{array}{l}\lambda_{\text {abs }}[\mathrm{nm}]: 667 \&\left[\mathrm{M}^{-1} \mathrm{~cm}^{-1}\right]: 55,000 \lambda_{\mathrm{em}}[\mathrm{nm}]: 668 \Phi \\
\text { [\%]: } 16 \mathrm{In} \text { ethanol }\end{array}$ & {$[129,130]$} \\
\hline Phthalocyanine & $\begin{array}{l}\text { Zinc } \\
\text { Phthalocyanine }\end{array}$ & & $\begin{array}{l}\lambda_{\text {abs }}[\mathrm{nm}]: 674 \varepsilon\left[\mathrm{M}^{-1} \mathrm{~cm}^{-1}\right]: 28 \mathrm{I}, 800 \lambda_{\mathrm{em}}[\mathrm{nm}]: 678 \\
\Phi[\%]: 30 \mathrm{In} \text { pyridine }\end{array}$ & {$[13 \mid-133]$} \\
\hline Cyanine & IR825 & & $\begin{array}{l}\lambda_{\text {abs }}[\mathrm{nm}]: 825 \&\left[\mathrm{M}^{-1} \mathrm{~cm}^{-1}\right]: 1.145 \times 10^{5} \Phi[\%]:<10 \\
\text { In methanol }\end{array}$ & [134] \\
\hline
\end{tabular}

results. $^{37,73}$ Gliadin is obtained from wheat and other cereals, being one of the main proteins in the composition of gluten. ${ }^{74}$ It has a molecular mass of $25-100 \mathrm{kDa}$, with hydrophobic and lightly polar characteristics. Gliadinbased NPs have been previously studied in applications regarding the controlled release and delivery of drugs. ${ }^{73}$ Another plant-based protein used for the development of NPs is legumin. One of the main advantages of legumin- based NPs in the biomedical application is their ability to covalently conjugate with diverse biological ligands, via inherent functional groups, for specific delivery and targeting of drugs at desired sites. Legumin is an essential protein present in peas and other leguminous seeds, having an average molecular weight of about $360 \mathrm{kDa}^{34}$

Moving forward, proteins derived from milk have also earned consideration as nanocarriers for hydrophobic 


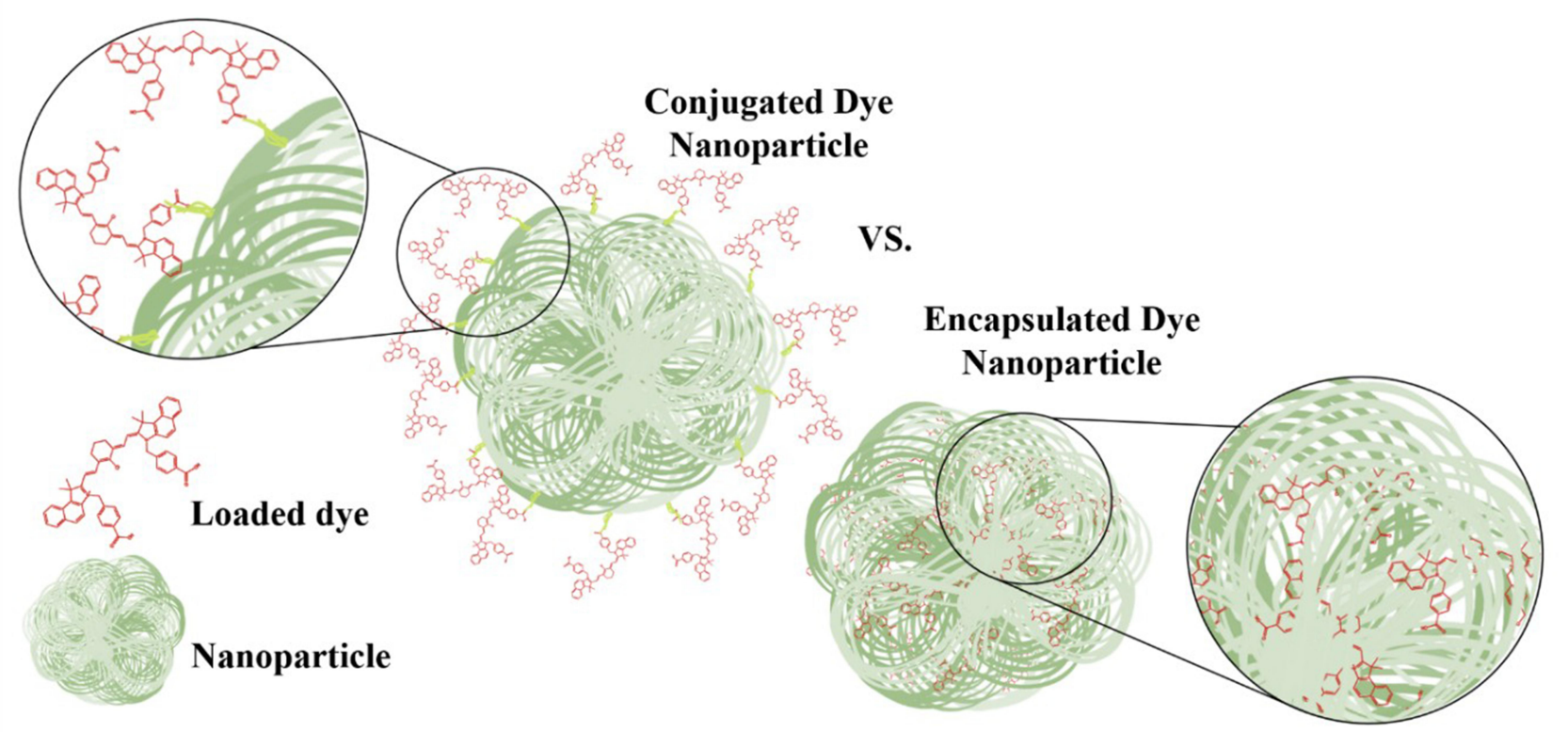

Figure 2 Schematic representation of conjugated versus (vs) encapsulated protein-based NPs with NIR emitting fluorophores.

anticancer drugs and other bioactive molecules since they are natural, cheap to manufacture and classified as GRAS. $^{48,50}$ The dominant protein in bovine milk is the flexible casein, with a molecular mass around $19-25 \mathrm{kDa}$, while $\beta$-Lactoglobulin, a small globular molecule with a molecular weight of $18.3 \mathrm{kDa}$, is the primary whey protein. ${ }^{73}$ A popular choice as a prime material in the synthesis of organic NPs for drug loading and delivery is gelatin, due to its biocompatibility, low cost, solubility in aqueous solutions and biodegradable character, ${ }^{75}$ having molecular weights reported between 15 and $400 \mathrm{kDa}^{76}$ Broadly, gelatin is obtained from type I collagen ${ }^{77}$ found in the bones, tendons, and skins of animals and has long been used in many industries, such as medical, pharmaceutical, cosmetics and food. ${ }^{78}$ As the name suggests, the biological catalysts formally known as enzymes (with

\section{Proteins used in the synthesis of NPs for fluorescence NIR medical imaging:}
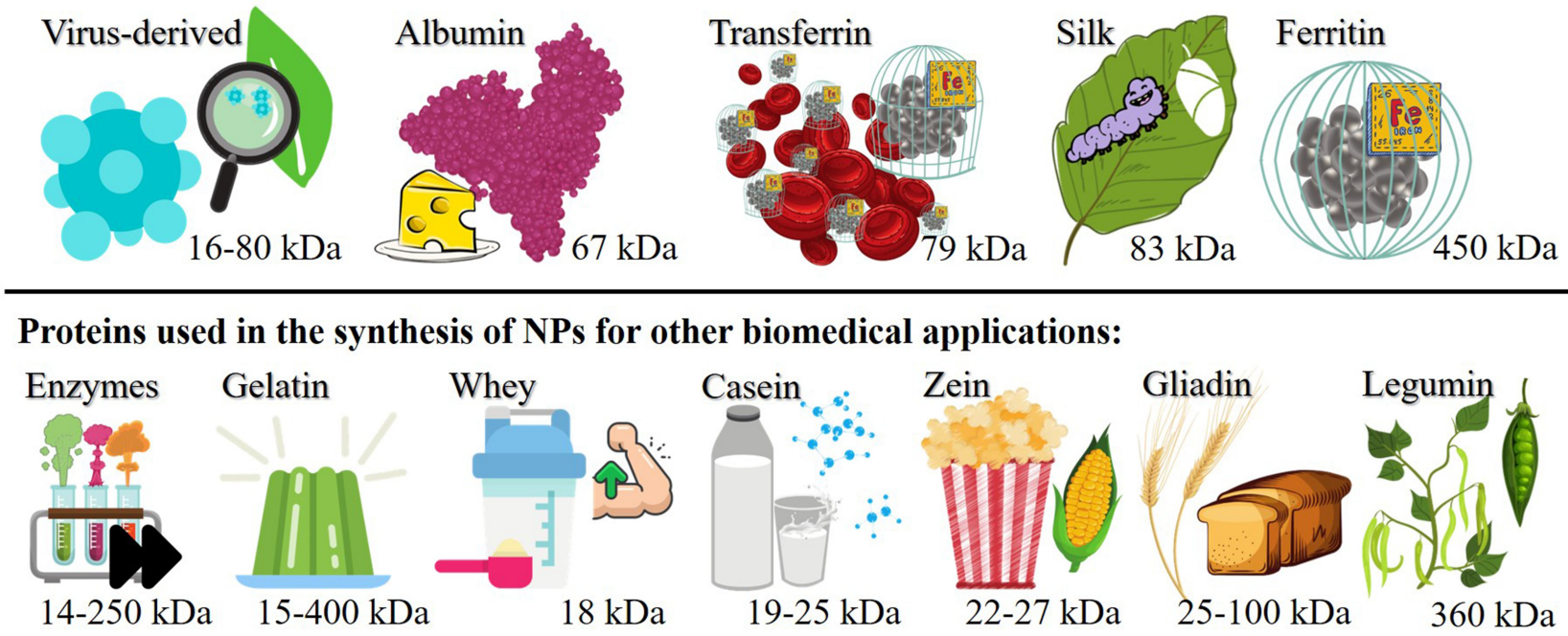

Figure 3 Proteins used for the synthesis of NPs loaded with NIR fluorophores for medical imaging (top line) or other biomedical applications (bottom line) and their molecular weights. 

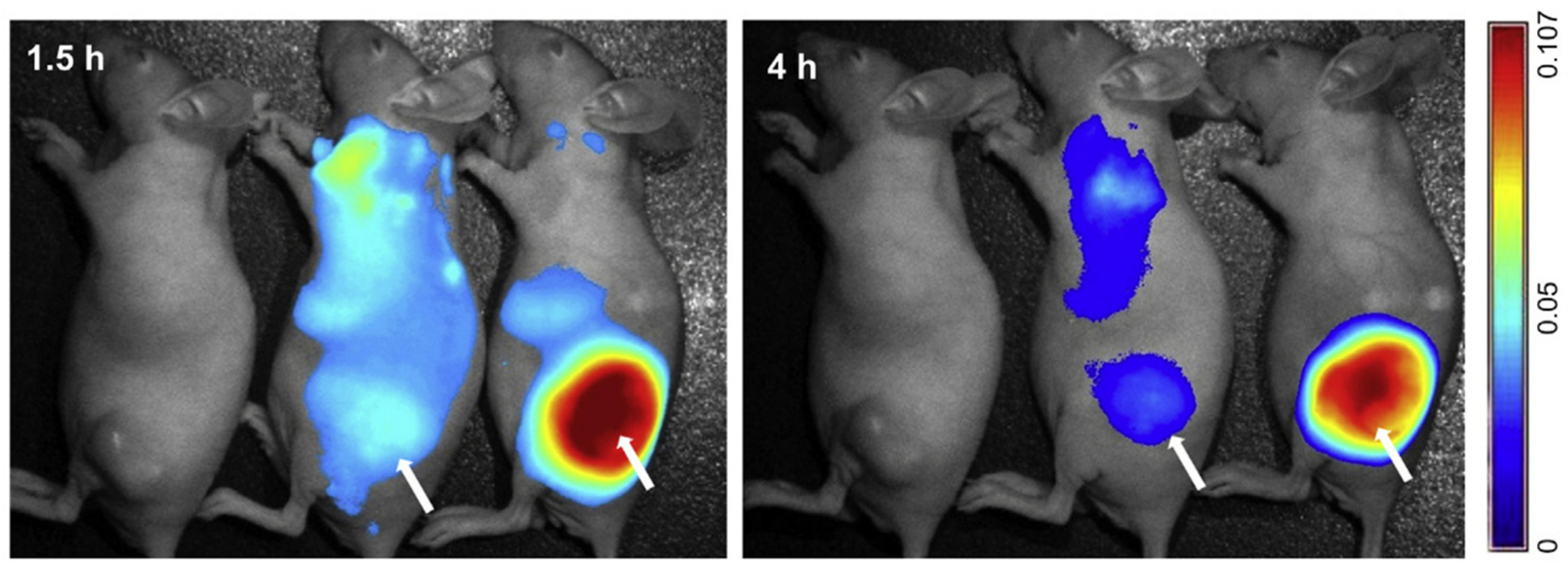

Figure 4 In vivo fluorescence imaging of nude mice bearing KB tumors at 1.5 and $4 \mathrm{~h}$ after injection of squaraine and BSA adducts and squaraine, BSA and folic acid adducts. Subcutaneous tumours locations are indicated by arrows. Reprinted from Biomaterials, 35, Gao FP, Lin YX, Li LL, et al. Supramolecular adducts of squaraine and protein for noninvasive tumor imaging and photothermal therapy in vivo. 1004-1014, copyright (2014), with permission from Elsevier. ${ }^{84}$

reported molecular weight ranging from 14 to 250 $\mathrm{kDa}^{79,80}$ ), are proteins able to significantly accelerate the rate of chemical reactions in living organisms, without consuming themselves in the process. ${ }^{81}$ Enzyme-based NPs attracted a lot of attention as biosensors with enhanced analytical performance and showed high potential as nano agents for delivering cargo. ${ }^{82,83}$

Although the above-mentioned types of protein-based NPs did not yet receive enough attention as candidates able to incorporate NIR dyes and serve as NIR fluorescence imaging agents, they display great potential for new research in this field.

\section{Squaraine-Loaded Nanoparticles}

Up to date albumin remains the cornerstone of proteinbased NPs, thanks to its biodegradability, biocompatibility and capacity to bind to a wide range of dyes, drugs, photosensitizers and other bioactive compounds. ${ }^{11,75}$ Albumin is the most abundant of the plasma proteins and for commercial purposes, albumin can be derived from egg white, rat serum, bovine serum (bovine serum albumin (BSA)) and human serum (the FDA approved human serum albumin (HSA)). Considering the similitude between the two heart-shaped proteins BSA (583 amino acids, $69.3 \mathrm{kDa}$ molecular weight) and HSA (585 amino acids, $66.5 \mathrm{kDa}$ molecular weight), a large number of bovine and human albumin-based NPs are currently tested in clinical trials. ${ }^{29,75}$ Albumin-based NPs gained popularity as contrast agents for medical imaging too, since they are able to encapsulate or conjugate to a large spectrum of dyes. One major benefit of loading NIR dyes in albumin- based NPs is brought to light in the work of Gao et al, ${ }^{84}$ an 80 -fold increase in the fluorescence intensity of iodinesubstituted squaraine $(713 \mathrm{~nm}$ free iodine-substituted squaraine emission maximum) after binding to BSA. Gao et al have demonstrated that the enhanced fluorescence intensity of the fluorophore can be associated with the release of the iodine-substituted squaraine molecules from $\mathrm{H}$-aggregates (typically present in free dye solutions) after the addition of BSA, once squaraine and BSA adducts are formed. In the same work, Gao et al performed in vitro and in vivo (Figure 4) studies by the use of squaraine and BSA adducts as fluorescence contrast agents for the NIR imaging of tumours.

\section{Porphyrin-Loaded Nanoparticles}

Among with their promising characteristics as agents for photodynamic therapy and photo-thermal therapy, porphyrin-loaded protein-based NPs have been investigated in vitro and in vivo as NIR fluorescence imaging agents for different types of cancers. Battogtokh et al ${ }^{85}$ studied the cellular uptake of free pheophorbide-a $(675 \mathrm{~nm}$ free pheophorbide-a emission maximum) in comparison with BSA-based NPs loaded with the same fluorophore in B16F10 (murine melanoma) and MCF-7 (human breast adenocarcinoma) cells. Since folate receptors are overexpressed on the surface of these cells, for a targeted delivery the fluorescent BSA-based NPs were conjugated with folic acid. The fluorescence intensity of B16F10 and MCF-7 cells was evaluated using a confocal laser scanning microscope after they were treated for 3 and $6 \mathrm{~h}$ with pheophorbide-a-loaded NPs and free pheophorbide-a. In both cases, 


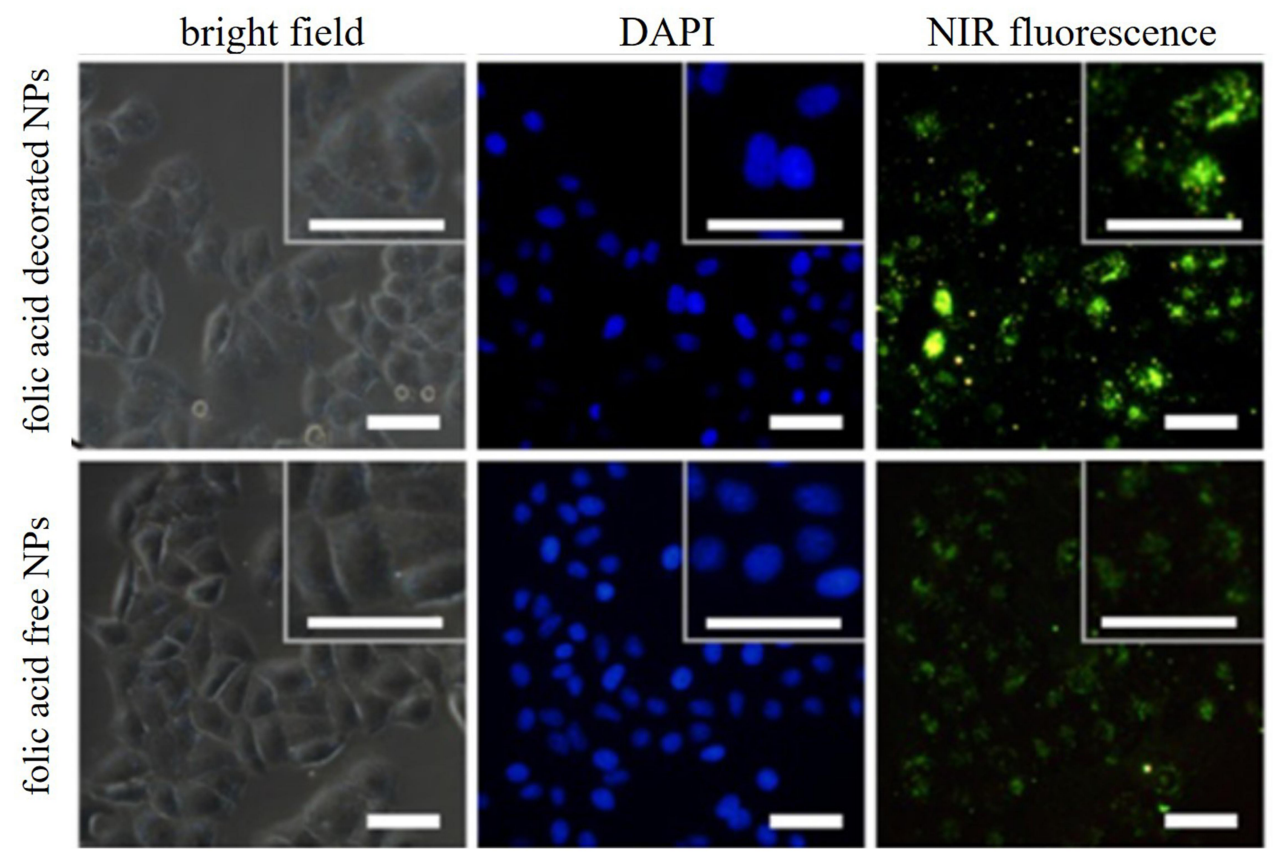

Figure 5 In vitro fluorescence imaging of HeLa cells treated for $4 \mathrm{~h}$ with folic acid decorate and free BSA-based zinc phthalocyanine loaded NPs. Scale bars represent $50 \mu \mathrm{m}$. Reprinted with permission from Dong C, Liu Z, Wang S, et al. A protein-polymer bioconjugate-coated upconversion nanosystem for simultaneous tumor cell imaging, photodynamic therapy, and chemotherapy. ACS Appl Mater Interfaces. 2016;8(48):32688-32698. Copyright (2016) American Chemical Society. ${ }^{88}$

folate targeted NPs showed and enhanced fluorescence intensity, and thus a better cellular internalization in comparison with cells treated with free pheophorbide-a. These results are in consonance with the in vivo and ex vivo assessments, indicating that, in contrast to free pheophorbide-a, folate-targeted pheophorbide-a-loaded BSA-based NPs accumulate preferentially at the tumour site.

Chen et $\mathrm{al}^{86}$ and $\mathrm{Hu}$ et $\mathrm{al}^{87}$ studied the potential of chlorin e6-loaded HSA-based NPs (668 nm free chlorin e6 emission maximum) as fluorescence imaging agents. The in vitro and in vivo investigations of the fluorescence intensities in U87MG (human primary glioblastoma) ${ }^{86}$ and $4 \mathrm{~T} 1$ (murine mammary carcinoma) ${ }^{87}$ cells revealed good cellular uptake and accumulation in tumours for the chlorin e6-loaded protein-based NPs. Moreover, by ex vivo fluorescence imaging of the tumours $\mathrm{Hu}$ et al determined an increase of the fluorescence intensity of almost 1050 times for the mice treated with chlorin e6-loaded protein-based NPs as to free chlorin e6.

\section{Phthalocyanine-Loaded Nanoparticles}

A different approach of using BSA in the synthesis of dye loaded NPs for medical imaging and cancer therapy is described in the study conducted by Dong et al. ${ }^{88}$ Dong et al designed a theranostic nanoplatform, loaded with zinc phthalocyanine fluorophore $(678 \mathrm{~nm}$ free zinc phthalocyanine emission maximum) and anticancer drug doxorubicin, with upconversion NPs serving as the core of the nanoplatform and a protein (BSA)-polymer shell. In vitro studies regarding the fluorescence emission of the zinc phthalocyanine-loaded NPs in HeLa cells (human cervical carcinoma) revealed their capability for real-time image guidance in combined cancer therapy (Figure 5).

\section{Cyanine-Loaded Nanoparticles}

Iron ions are used by living cells for a multitude of tasks, eg the transport of oxygen, synthesis of DNA, electron transfer, cell proliferation and metabolism, thus it is no surprise that there are specialized proteins for the storage and transport of iron. Ferritin proteins have a cage-like structure with inner and outer diameters of 8 and $12 \mathrm{~nm}$, respectively, and can accumulate and store, in a bioavailable manner, up to 4500 atoms of iron. ${ }^{75}$ They have a molecular mass of $450 \mathrm{kDa}$ and are abundant in our body, especially in the spleen, liver, bone marrow and skeletal muscle, but not much ferritin can be found in the blood. ${ }^{89}$ Since ferritins are biocompatible, biodegradable and have a hollow structure, they make excellent candidates for a large number of biomedical applications. ${ }^{75}$ Ferritin-based NPs labeled with a NIR 


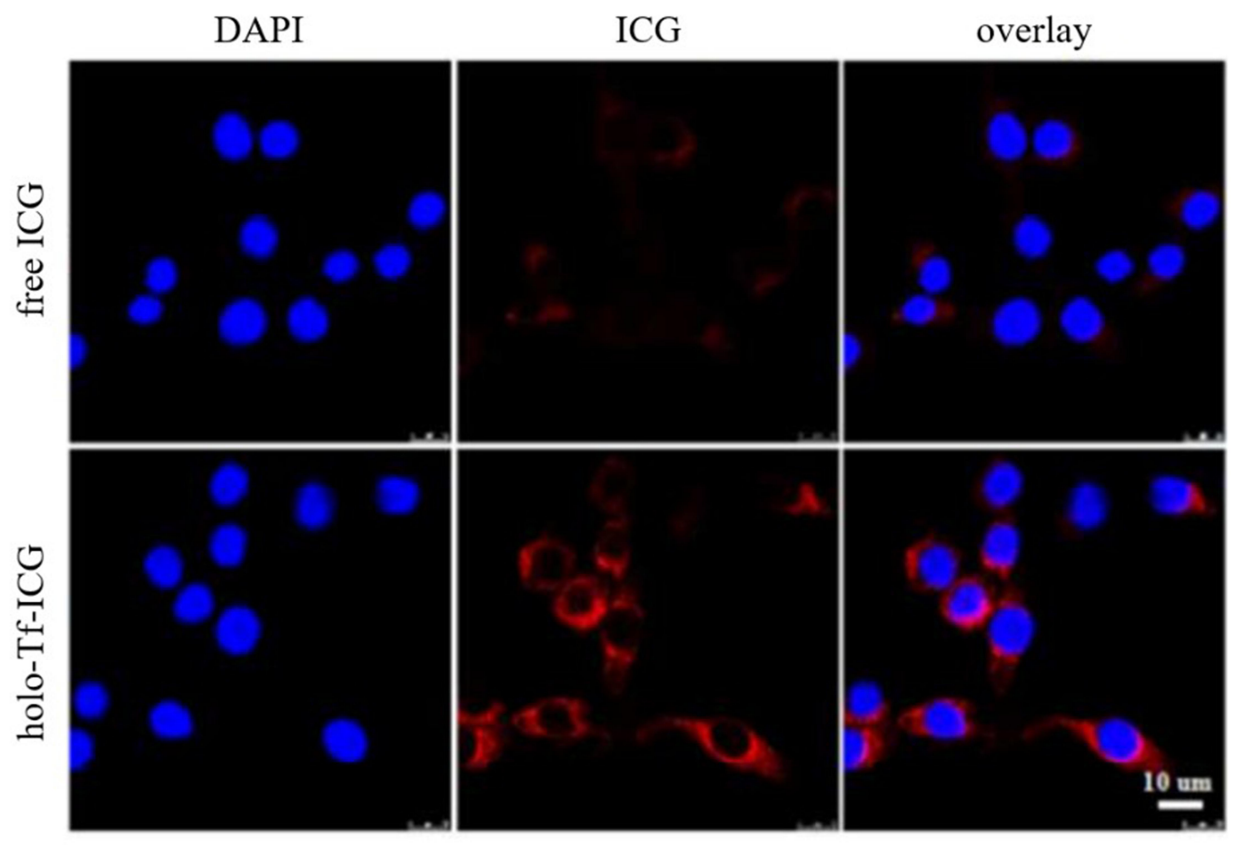

Figure 6 In vitro fluorescence imaging of U87 cells treated for $4 \mathrm{~h}$ with free ICG (top) vs transferrin-based ICG loaded NPs (bottom). Reprinted with permission from Zhu M, Sheng Z, Jia Y, et al. Indocyanine green-holo-transferrin nanoassemblies for tumor-targeted dual-modal imaging and photothermal therapy of glioma. ACS Appl Mater Interfaces. 2017;9:39249-39258. Copyright year (2017) American Chemical Society. ${ }^{94}$

dye, namely ZW800 (800 nm free ZW800 emission maximum), have been investigated in vitro and in vivo by Zhen et $\mathrm{al}^{90}$ as fluorescent contrast agents. Cellular uptake studies have been carried out with U87MG cells (human primary glioblastoma). In vivo and ex vivo fluorescence imaging investigations performed on athymic nude mice subcutaneously injected with the same cell line pointed out good tumour accumulation.

As the name implies, transferrin is the protein responsible for the transport of iron through our body and has a molecular mass of $79 \mathrm{kDa} .{ }^{75}$ Transferrin proteins can carry two atoms of iron(III) and deliver them wherever needed via transferrin receptor-mediated endocytosis. ${ }^{91}$ Given that different types of cancer present an overexpression of transferrin receptors on the surface of the cells, targeted delivery of drugs and other therapeutic and imaging agents can be achieved by designing transferrin-based NPs for medical applications. ${ }^{75}$ Kang et al $^{92}$ evaluated in vitro the Cy5.5 loaded transferrin-based NPs (694 nm free Cy5.5 emission maximum) as NIR fluorescence imaging agents with cells known for overexpressing transferrin receptors, eg HeLa (human cervical carcinoma), HT29 (human colorectal adenocarcinoma) and PC3 (human prostate carcinoma) cells. After treatment with transferrin- based NPs conjugated with Cy5.5 dye, fluorescence signals were detected for all cell lines, while no relevant intranuclear internalization of the NPs was observed. Peng et $\mathrm{al}^{93}$ developed multifunctional transferrin-based NPs conjugated with Cy7 dye (773 nm free Cy7 emission maximum) for targeting, imaging and therapy of cancer. After injection with the Cy7 conjugated NPs, the in vivo fluorescence imaging investigation of nude mice bearing A549 cells (human alveolar epithelial carcinoma) concluded a maximum fluorescence emission at $8 \mathrm{~h}$ after the treatment. The in vitro study conducted by $\mathrm{Zhu}$ et al ${ }^{94}$ with U87MG cells (human primary glioblastoma) revealed an increase of 2.4-fold of the fluorescence intensity observed after treatment with transferrin-based ICG-loaded NPs in comparison with the fluorescence signal of cells treated with free ICG (830 $\mathrm{nm}$ free ICG emission maximum). At $24 \mathrm{~h}$ post injection of NPs and free ICG to nude mice bearing U87MG cells, in vivo studies showed an impressive 38-fold increase of the fluorescence signal in the tumour site for the group treated with transferrin-based ICG loaded NPs vs free ICG (Figure 6). Moreover, for mice with orthotopic brain tumours no fluorescence signal was detected when treated with free ICG, in contrast with the transferrin-based NPs treated group that showed the 
maximum fluorescence intensity $24 \mathrm{~h}$ after injection. These results support their ability to cross the bloodbrain barrier and their enhanced targeting and tumour penetration capabilities.

Silk proteins, the products of diverse silkworms, are naturally biodegradable and biocompatible polymeric biomaterials, with a molecular weight of around $83 \mathrm{kD} .{ }^{95}$ Thanks to their auspicious properties against thermal denaturation, dissolution and enzymatic degradation, silk-based NPs can be used as carriers for drugs and other therapeutic agents in biomedical and pharmaceutical applications. Another advantage of silk protein is the abundance of amino acids with functional groups in their structure that facilitate their bioconjugation with various targeting ligands. ${ }^{96}$ Liu et al $^{97}$ investigated in vivo the accumulation at the tumour site of NIR-797 isothiocyanate-loaded silk NPs conjugated with iRGD-EGFR recombinant protein for specific targeting (814 $\mathrm{nm}$ free NIR-797 isothiocyanate emission maximum), and a control group without targeting properties. Balb/c (nu/nu) mice subcutaneously injected with HeLa cells (human cervical carcinoma) presented fluorescence signal at the tumour site $4 \mathrm{~h}$ post injection with both fluorescent silk-based NPs. However, mice treated with the specific targeting NPs group reached the maximum fluorescence intensity and accumulation at the tumour site $24 \mathrm{~h}$ after injection, while the control group achieved maximum fluorescence intensity after $144 \mathrm{~h}$. At $168 \mathrm{~h}$ post administration, ex vivo investigations confirmed similar fluorescence signal in the tumour and liver for non-targeting silk NPs, while for the iRGD-EGFR recombinant protein-conjugated silk-based NPs, the fluorescence signal emitted from the liver was lower than that coming from the tumour; no significant fluorescence emission was found in other tissue for both groups of NIR-797 isothiocyanate-loaded silk NPs.

Virus-derived proteins (with molecular weight ranging from 16 to $80 \mathrm{kDa}^{68}$ ) gained attention as nano agents for their suitable characteristics in a large variety of biological and medical applications, such as diagnosis, therapy and disease prevention. $^{29}$ Of course, for the manufacture of virus-derived NPs only the noninfectious part of the virus protein is used. Their stability, biocompatibility and their ability to deliver biomolecules, enzymes, drugs, and other bioactive molecules made virus-derived NPs broadly used as nanocarriers and for vaccine design. ${ }^{82} \mathrm{Hu}$ et $\mathrm{al}^{98}$ studied tobacco mosaic virus-based NPs loaded with the NIR Cy7.5 dye (808 nm free Cy7.5 emission maximum) in vitro with PC3 cells (human prostate carcinoma) and in vivo in nude mice subcutaneously injected with the same cell line. Since PC3 cells present on their surface an overexpression of $\alpha_{2} \beta_{1}$ integrin, the cells and mice were treated with control fluorescent virus-based NPs (nontargeting) and NPs bioconjugated with an Asp-Gly-GluAla peptide for specific targeting. The in vitro investigations revealed a 1.5-fold increase of the fluorescence signal for the cells treated with the targeting NPs, and a fluorescence intensity dependent on the concentration of the NPs administered was observed for cells treated with both targeting and non-targeting virus-based NPs. In vivo studies concluded that maximum accumulation of the fluorescent virus-based NPs in the tumour site occurs 6 $\mathrm{h}$ after the injection, measuring a 2.5-fold enhancement in the fluorescence intensity for the group treated with the targeting NPs. The ex vivo fluorescence imaging confirmed the difference in the fluorescence intensity in tumour and other tissues.

Albumin-based NPs have also been investigated for loading NIR cyanine dyes as imaging agents in different kinds of biomedical applications. Cy5-loaded HSA-based NPs conjugated with the photo-activatable Pt(IV) antitumour prodrug (667 nm free Cy5 emission maximum) have been synthesized and studied in vitro by $\mathrm{Li}$ et $\mathrm{al}^{99}$ with A2780 and A2780 cisplatin-resistant cells (human ovarian carcinoma). The localized activation by UV light irradiation of photoactive $\mathrm{Pt}(\mathrm{IV})$ drug within the tumour causes cellular death and generates the activation of caspase 3, leading to the turn-on fluorescence effect of Cy5. In this manner, Li et al archived real-time NIR imaging on controlled drug release together with the assessment of parallel antitumour effects. Chen et al ${ }^{100}$ loaded both ICG and Cy5.5 onto HSA-based NPs to investigate the in vitro (Cy5.5 as imaging agent) and in vivo (ICG as imaging agent) cellular internalization and tumour accumulation with MCF-7 cells (human breast adenocarcinoma) and in nude mice subcutaneously injected with MCF-7 cells, respectively. The in vitro imaging investigations demonstrated the colocalization of the fluorescent HSA-based NPs and lysosomes indicating endocytosis as the preferred pathway for cellular uptake of the NPs. The fluorescence intensity of the HSA-based NPs in cells increased over time. The circulation time in vivo of free ICG solution was determined to be up to $8 \mathrm{~h}$, in contrast to the circulation time of ICG when loaded to HSA NPs, even more than 24 $\mathrm{h}$ after injection. The maximum fluorescence intensity at the tumour site of the ICG-loaded HSA NPs was measured $8 \mathrm{~h}$ after administration. Ex vivo fluorescence imaging 
confirmed the increased tumour accumulation of the HSAbased NPs in comparison with other major organs. The in vitro cellular uptake and in vivo tumour targeting abilities of ICG-loaded albumin-based NPs with MCF-7 cells (human breast adenocarcinoma) have been also studied by $\mathrm{Xu}$ et al. ${ }^{101}$ The cellular internalization of the $100 \mathrm{~nm}$ in diameter ICG-loaded BSA NPs has been compared with a group of cells treated with ICG-loaded BSA NPs conjugated with a cell-penetrating peptide (KALA), and a third group of cells treated with ICG-loaded BSA NPs conjugated with KALA and a tumour-targeting aptamer (AS1411). As anticipated, the properties of KALA to destabilize the lipid membrane of cells leads to a more abundant internalization of the NPs, in comparison with cells treated with the nonconjugated fluorescent BSAbased NPs. However, the highest fluorescence signal was measured for the cells treated with ICG-loaded BSA NPs conjugated with KALA and AS1411, thanks to the binding capability of the aptamer with the overexpressed nucleolin in MCF-7 cells. In vivo investigations on tumour bearing mice revealed a maximum of the fluorescence intensity at the tumour site $8 \mathrm{~h}$ post injection with the ICG-loaded BSA NPs conjugated with KALA and AS1411, and at 24 $\mathrm{h}$ after administration, the fluorescence signal remains relatively strong. The ex vivo fluorescence imaging of the tumour and other major organs concluded a better accumulation of the ICG-loaded BSA NPs conjugated with KALA and AS1411 in the tumour. Sahu et $\mathrm{al}^{102}$ developed $33 \mathrm{~nm}$ BSA-based NP loaded with ICG and studied in vivo their biodistribution and tumour targeting ability in contrast with free ICG solution, by NIR fluorescence imaging in athymic nude mice subcutaneously injected with SCC7 cells (murine squamous carcinoma). At $3 \mathrm{~h}$ after the treatment with free ICG solution, a high fluorescence intensity was observed in the liver of the mice and it slowly decreased over time indicating a short circulation time for free ICG. Also, only a weak fluorescence signal was measured $24 \mathrm{~h}$ post injection at the tumour site. In contrast, while a strong fluorescence signal was observed through the whole body at 3 and $6 \mathrm{~h}$ post administration of the ICG-loaded BSA NPs, at 12 and 24 $\mathrm{h}$ after the injection, in all mice, the highest fluorescence intensity was observed at the tumour site. Ex vivo NIR imaging at $24 \mathrm{~h}$ post treatments revealed a low fluorescence signal in all major organs and a high accumulation of the ICG-loaded BSA NPs in the tumour, in contrast with tumours from mice treated with free ICG, that presented a low fluorescence intensity in tumours and higher intensities in other organs, eg liver, lung.

A widely studied NIR contrast agent for the fluorescence imaging of a broad variety of cancer types are the versatile, biocompatible, and biodegradable ICG-loaded HSA NPs. These albumin-based NPs have been designed in different sizes and have been functionalized with various ligands in order to optimize and study in vivo and in vitro their targeting and delivering performances and offer the possibility of better and personalized treatments in the near future. Chen et $\mathrm{al}^{103}$ and Sheng et al ${ }^{104}$ investigated the in vivo tumour accumulation and biodistribution of ICG-loaded HSA NPs intravenously injected into nude mice bearing tumours, after being subcutaneously injected with 4T1 cells (murine mammary carcinoma). Both studies reported a prolonged blood circulation halflife of ICG-loaded HSA NPs compared to the half-life of free ICG, probably mediated by the EPR effect considering the increased sizes of the HSA-based NPs correlated to the size of the free dye molecules. The prolonged half-life of the ICG-loaded HSA NPs is once again brought to light in both studies by the ex vivo fluorescence imaging investigations at $24 \mathrm{~h}$ after treatments; the ICG accumulation in tumours when loaded onto HSA-based NPs is significantly increased compared to other major organs, as well as in contrast to tumours collected from mice treated with free ICG solution or ICG-HSA complex solution. In addition, Sheng et al considered the in vitro cellular uptake of free ICG and ICG-loaded HSA NPs with 4T1 cells. At $3 \mathrm{~h}$ after incubation, cells treated with the free ICG solution showed weak fluorescence intensity in parallel with cells treated with the ICG-loaded HSA NPs. The in vitro study conducted by Borlan et al ${ }^{105}$ on NIH:OVCAR3 cells (human ovarian carcinoma) indicated a good cellular internalization of the ICG loaded HSA NPs via endocytic vesicles 24 $\mathrm{h}$ after incubation. The in vitro and in vivo behaviour of ICG loaded HSA NPs conjugated with folic acid, for the active targeting of the folate receptor alpha present in most HepG2 cells (human hepatocellular carcinoma) was discussed in the work of Yang et al. ${ }^{106}$ The in vitro investigations concluded a better cellular internalization for the cells treated with the ICG loaded HSA NPs conjugated with folic acid, in comparison with cells treated with free ICG or untargeted fluorescent HSA-based NPs. The in vivo fluorescence signal in the tumour site increased over time for mice treated with either free ICG or targeted/ untargeted NPs, reaching a maximum fluorescence intensity $24 \mathrm{~h}$ after administration. Still, at any tested time 
point, the fluorescence intensity for the group treated with targeted HSA-based NPs was greater than that of the other two groups. At $24 \mathrm{~h}$ post injection, ex vivo fluorescence imaging of all examined groups related high fluorescence intensities in the liver.

\section{Heptamethine-Loaded Nanoparticles}

For a better stability and fluorescence quantum yield than the FDA approved and widely used ICG fluorophore, Rong et $\mathrm{al}^{107}$ designed a heptamethine $\mathrm{CySCOOH}$ dye (840 $\mathrm{nm}$ free $\mathrm{CySCOOH}$ emission maximum) by the introduction of a rigid cyclohexenyl ring to the heptamethine chain, and covalently conjugated the NIR dye to HSA-based NPs. The in vivo efficiency as NIR imaging agents of CySCOOH-loaded HSA NPs, in parallel with free $\mathrm{CySCOOH}$ solution, was investigated in nude mice subcutaneously injected with MCF-7 cells (human breast adenocarcinoma). At only 10 minutes post administration, both tested groups presented fluorescence signal through the whole body, and, in time, an increase of the fluorescence intensity in the tumour site and a decrease of the signal in the whole body was observed for the $\mathrm{CySCOOH}-$ loaded HSA NPs group. In time, the mice injected with free $\mathrm{CySCOOH}$ solution presented a decrease in the fluorescence signal in the whole body, thus at $1 \mathrm{~h}$ post administration, a high percentage of the dye is localized in the spleen and is eliminated from the circulation in less than 24 h. HSA-based NPs have also been complexed with a newly developed NIR dye, with high fluorescence intensity and preferential accumulation within malignant tissue, ${ }^{108}$ precisely IR780 iodide $(810 \mathrm{~nm}$ free IR780 iodide emission maximum), by Han et al. ${ }^{109}$ In vitro fluorescence imaging with BxPC-3 cells (human pancreatic carcinoma) confirmed the cellular uptake of the IR780loaded HSA NPs once the fluorescence intensity in the cytoplasm of the cell enhanced over time. The fluorescence signal of IR780-loaded HSA NPs examined by in vivo NIR imaging on nude mice subcutaneously injected with BxPC-3 cells remained very strong within the tumour even $72 \mathrm{~h}$ after administration. IR780-loaded transferrin NPs have been investigated by Wang et al ${ }^{110}$ with CT26 cells (murine colorectal carcinoma) and the noncancerous L929 cells (murine fibroblast) for control, as imaging agents for specific targeting of cancerous cells due to their ability to bind to the transferrin receptors exposed on the surface of most cancerous cells, in contrast to normal cells. In vitro fluorescence imaging experiments showed an increased fluorescence intensity after an incubation of $2 \mathrm{~h}$ for the CT26 cells treated with IR780loaded transferrin NPs, compared with the control cells. The in vivo tumour accumulation and biodistribution was evaluated on mice subcutaneously injected with CT26 cells, after the administration of the IR780-loaded transferrin NPs. The fluorescence signal in the tumour site came to a maximum at $48 \mathrm{~h}$ after administration. Ex vivo imaging $24 \mathrm{~h}$ post injection indicated an enhanced accumulation of the IR780-loaded transferrin NPs in the tumour than in other major organs.

Cohen et $\mathrm{al}^{111,112}$ synthesized and loaded a carboxylic acid derivative of the IR783 dye (CANIR) to HSA-based NPs and then covalently conjugated them with diverse ligands (anti-carcinoembryonic antigen antibodies (antiCEA), peanut agglutinin (PNA)) for the detection of colon tumours ( $818 \mathrm{~nm}$ free CANIR emission maximum). The in vitro cellular uptake and active targeting of CANIR-loaded HSA NPs has been investigated with three different lines of human colorectal adenocarcinoma cells: the CEA overexpressing LS174T cells and HT29 cell line as a control group, with CEA exposed to a significantly lower degree. SW480 cells were used as a control group with low expression of the ThomsenFriedenreich antigen (PNA binds preferentially to it), an antigen upregulated in numerous colorectal adenocarcinoma cell lines, including LS174T and HT29 cells. The fluorescence intensity of the LS174T cells treated with the CEA targeting CANIR-loaded HSA NPs was above the fluorescence intensity measured for the CEA nontargeting NPs, and 6 times higher in comparison with the control group, the HT29 cells treated with CANIR-loaded HSA NPs conjugated with anti-CEA. Similar performances were observed for LS174T and HT29 cells when treated with CANIR-loaded HSA NPs conjugated with PNA, a much-increased fluorescence intensity (7 times greater) in relation to the fluorescence signal measured for the control SW480 cells after treatment with the same HSAbased NPs. In vivo investigations on Sabra rats with DMH-induced polyps treated with CANIR-loaded HSA NPs conjugated with PNA showed high accumulation of the NPs at the tumour site, measuring a fluorescence intensity 15.5 times higher in comparison with the fluorescence intensity of the surrounding non-cancerous tissue. Nude mice with orthotopic-tumours originate from injection of LS174T cells to the colon wall, were treated with CANIRloaded HSA NPs conjugated with PNA in order to determine the optimal recovery time between NPs administration and fluorescence imaging of the colon tumours. 
Cohen et al concluded that for a good fluorescence signal (of the tumour site) to background (the surrounding noncancerous tissue) ratio a $4 \mathrm{~h}$ recovery time is needed when imaging colorectal cancer.

Over the past few years, the fluorescence imaging properties of IR825 loaded HSA NPs have been studied both in vitro and in vivo in different settings. Chen et $\mathrm{al}^{113}$ examined with $4 \mathrm{~T} 1$ cells (murine mammary carcinoma) the in vitro cellular uptake of IR825 loaded HSA NPs and their position relative to lysosomes, indicating a time-dependent internalization mediated by endocytosis. After administrating IR825 loaded HSA NPs to tumour-bearing mice, fluorescence images with good contrast of the tumour site were noticed 1 to 12 $\mathrm{h}$ post injection, with the maximum fluorescence signal measured $2 \mathrm{~h}$ after the administration of the HSA-based NPs. The good accumulation of the IR 825 loaded HSA NPs into the tumour at $2 \mathrm{~h}$ after the injection, in comparison with other major organs, was also confirmed by ex vivo fluorescence imaging. The time-dependent cellular internalization of HSA-based NPs loaded with IR825 was also demonstrated in a different study by
Chen et $\mathrm{al}^{114}$ with $4 \mathrm{~T} 1$ cells (murine mammary carcinoma). When mice subcutaneously injected with 4T1 cells were administered with IR825 loaded HSA NPs, in addition to the expected fluorescence signal measured for the tumour site, the NIR fluorescence imaging investigations revealed a strong fluorescence intensity for the sentinel lymph node nearby the tumour site, reaching a maximum at $30 \mathrm{~min}$ post administration. The good accumulation of the IR825 loaded HSA NPs in the sentinel lymph node was also confirmed by ex vivo imaging. Gao et $\mathrm{al}^{115}$ examined the in vitro cellular uptake of IR825 loaded HSA NPs in parallel with free IR825 solution, with A549 cells (human alveolar epithelial carcinoma). At any given incubation time tested, the fluorescence signal of the cells treated with the free IR825 solution was much lower than that of cells treated with the IR825 loaded HSA NPs. These results are confirmed by in vivo fluorescence imaging investigations carried out on tumour bearing mice, after administration with free IR825 solution and IR825 loaded HSA NPs. The control group treated with free IR825 showed low fluorescence intensity in the tumour site,

Table 2 Features and Use of Protein-Based NP Loaded with Squaraine, Porphyrin and Phthalocyanine NIR Dyes for Interventional Fluorescence Imaging of Cancer in Preclinical Studies

\begin{tabular}{|c|c|c|c|c|c|c|c|c|}
\hline $\begin{array}{l}\text { Fluorophore } \\
\text { Class }\end{array}$ & $\begin{array}{l}\text { NIR } \\
\text { Fluorophore }\end{array}$ & $\begin{array}{l}\text { Emission } \\
\text { Maximum } \\
(\mathrm{nm})\end{array}$ & Protein & $\begin{array}{l}\text { Size } \\
(\mathrm{nm})\end{array}$ & $\begin{array}{l}\text { In vitro } \\
\text { NIR } \\
\text { Imaging } \\
\text { Cell Line }\end{array}$ & $\begin{array}{l}\text { Preclinical in vivo } \\
\text { (ex vivo) NIR } \\
\text { Imaging Model }\end{array}$ & $\begin{array}{l}\text { Preclinical in vivo (ex } \\
\text { vivo) Imaging Setup }\end{array}$ & Ref \\
\hline Squaraine & $\begin{array}{l}\text { lodine- } \\
\text { substituted } \\
\text { squaraine }\end{array}$ & $713^{126}$ & BSA & 11 & $K B$ & $\begin{array}{l}\text { Female Balb/c nude } \\
\text { mice subcutaneously } \\
\text { injected with KB } \\
\text { cells }\end{array}$ & $\begin{array}{l}680 \mathrm{~nm} \text { excitation; } \\
\text { Maestro in vivo imaging } \\
\text { system }\end{array}$ & [84] \\
\hline \multirow[t]{3}{*}{ Porphyrin } & $\begin{array}{l}\text { Pheophorbide- } \\
\text { a }\end{array}$ & $675^{135}$ & BSA & 182 & $\begin{array}{l}\text { BI6FIO } \\
\text { and MCF-7 }\end{array}$ & $\begin{array}{l}\text { Balb/c athymic nude } \\
\text { mice subcutaneously } \\
\text { injected with MCF-7 } \\
\text { cells }\end{array}$ & $\begin{array}{l}605-720 \mathrm{~nm} \text { emission } \\
\text { filter; IVIS optical } \\
\text { imaging system }\end{array}$ & [85] \\
\hline & Chlorin e6 & $668^{130}$ & HSA & $\begin{array}{l}50 \\
\text { and } \\
100\end{array}$ & U87MG & $\begin{array}{l}\text { Female nude mice } \\
\text { subcutaneously } \\
\text { injected with } \\
\text { U87MG cells }\end{array}$ & $\begin{array}{l}661 \mathrm{~nm} \text { excitation; } \\
700-850 \mathrm{~nm} \text { emission } \\
\text { filter; Maestro in vivo } \\
\text { imaging system }\end{array}$ & [86] \\
\hline & Chlorin e6 & $668^{130}$ & HSA & 100 & $4 \mathrm{TI}$ & $\begin{array}{l}\text { Male Balb/c athymic } \\
\text { nude mice } \\
\text { subcutaneously } \\
\text { injected with 4TI } \\
\text { cells }\end{array}$ & $\begin{array}{l}605 \mathrm{~nm} \text { excitation; } 635 \\
\mathrm{~nm} \text { emission filter; } \\
\text { Maestro in vivo imaging } \\
\text { system }\end{array}$ & [87] \\
\hline Phthalocyanine & $\begin{array}{l}\text { Zinc } \\
\text { phthalocyanine }\end{array}$ & $678^{133}$ & BSA & 45 & HeLa & - & - & [88] \\
\hline
\end{tabular}




\begin{tabular}{|c|c|c|c|c|c|c|c|c|c|c|c|c|c|c|}
\hline 岀 & $\overline{2}$ & 合 & $\sigma$ & $\bar{\sigma}$ & $\sqrt{\alpha}$ & $\stackrel{\mathscr{D}}{\circ}$ & 은 & F & 존 & $\overline{\overline{ }}$ & 守 & $\underline{\underline{\underline{O}}}$ & 믕 & 은 \\
\hline 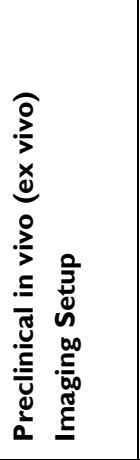 & 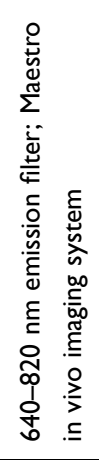 & 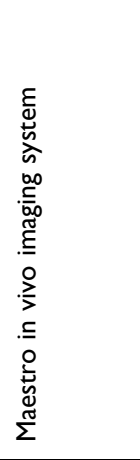 & 1 & 1 & 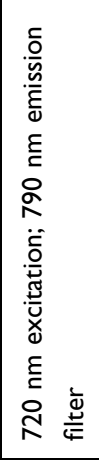 & 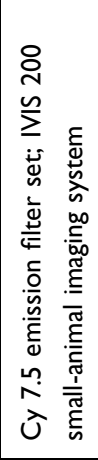 & 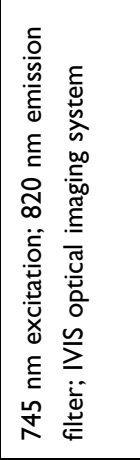 & 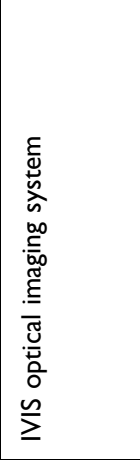 & 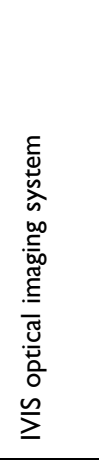 & 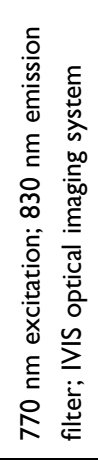 & 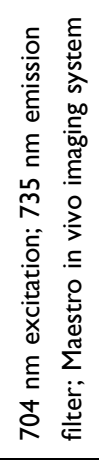 & 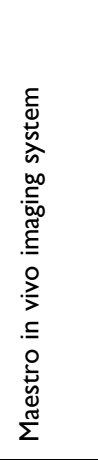 & 1 & 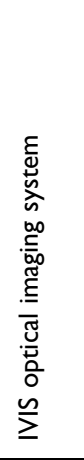 \\
\hline 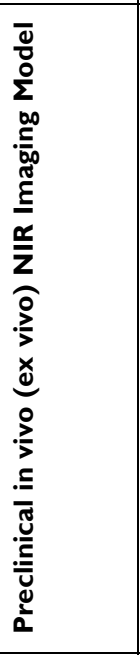 & 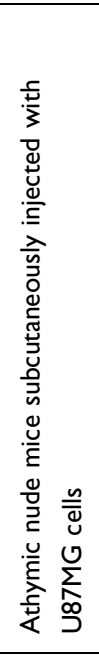 & 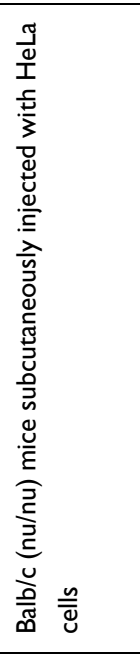 & 1 & 1 & 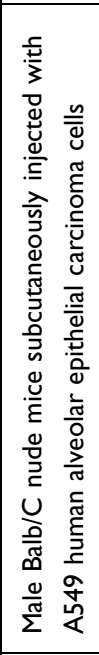 & 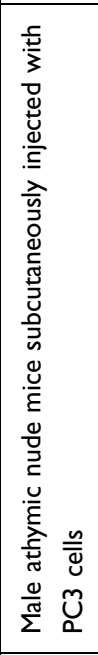 & 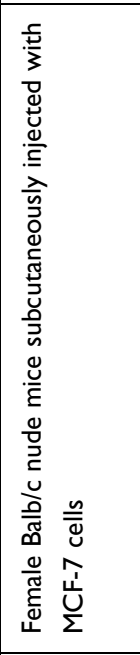 & 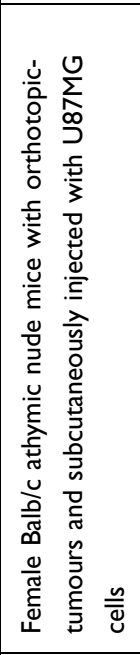 & 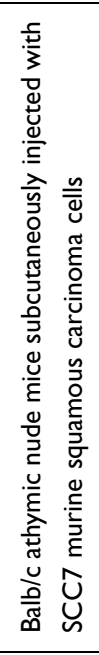 & 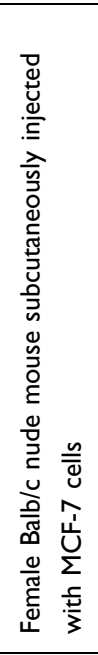 & 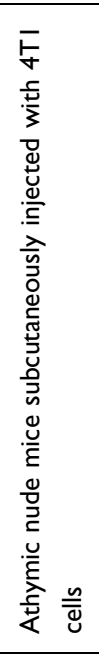 & 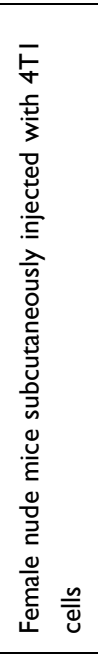 & 1 & 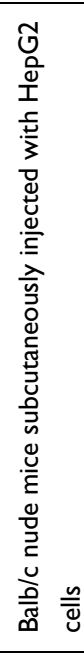 \\
\hline 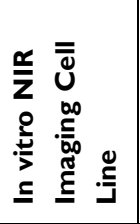 & 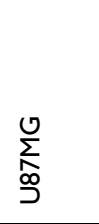 & 1 & 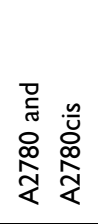 & 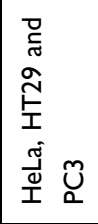 & 1 & $\tilde{O}$ & $\begin{array}{l}\hat{U} \\
\stackrel{U}{\Sigma}\end{array}$ & $\sum_{\substack { 0 \\
\begin{subarray}{c}{0 \\
د{ 0 \\
\begin{subarray} { c } { 0 \\
د } }\end{subarray}}^{U}$ & I & $\begin{array}{c}\hat{U} \\
\dot{U}\end{array}$ & F & I & 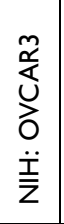 & $\begin{array}{l}\text { ত̃ } \\
\frac{a}{I} \\
\frac{0}{I}\end{array}$ \\
\hline 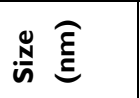 & $\underline{a}$ & 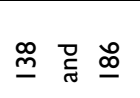 & ஓ्ন & 1 & ণ & ờ & $\bar{\beth}$ & 으 & $m$ & $\underline{\underline{ }}$ & n & $\bowtie$ & $\stackrel{\sim}{\sim}$ & $\overline{\underline{m}}$ \\
\hline 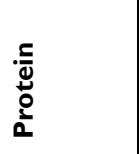 & 高 & 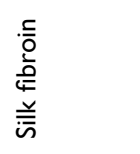 & 吕 & 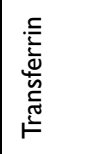 & 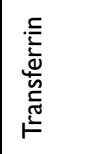 & : & 蒙 & 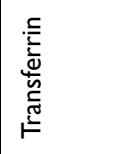 & 吕 & 杀 & 艿 & 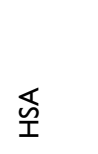 & $\begin{array}{l}\mathbf{x} \\
\text { 殅 } \\
\end{array}$ & 艿 \\
\hline 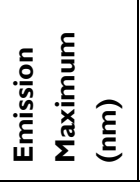 & \& & $\frac{\mathscr{\infty}}{\frac{\sigma}{\infty}}$ & $\frac{\hat{m}}{\widehat{s}}$ & 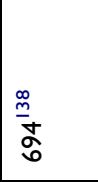 & $\frac{\stackrel{o}{m}}{\mathfrak{m}}$ & $\begin{array}{l}\stackrel{\alpha}{m} \\
\infty \\
\infty \\
\infty\end{array}$ & 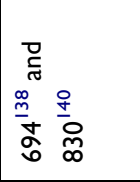 & \begin{tabular}{|l} 
\\
0 \\
0 \\
$\infty$
\end{tabular} & $\begin{array}{l}\frac{8}{9} \\
0 \\
\infty \\
\infty\end{array}$ & $\begin{array}{l}\frac{8}{0} \\
\stackrel{\infty}{\infty} \\
\infty\end{array}$ & $\begin{array}{l}\frac{9}{9} \\
0 \\
\infty \\
\infty\end{array}$ & $\begin{array}{l}\frac{9}{0} \\
\stackrel{0}{\infty} \\
\infty\end{array}$ & $\begin{array}{l}\frac{8}{0} \\
0 \\
\infty \\
\end{array}$ & $\begin{array}{l}\frac{q}{q} \\
0 \\
\infty \\
\infty\end{array}$ \\
\hline 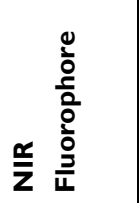 & 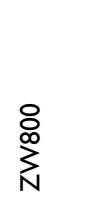 & 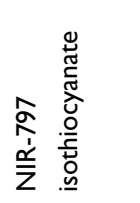 & Uు & 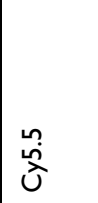 & 令 & $\stackrel{\stackrel{n}{\sim}}{\hat{U}}$ & 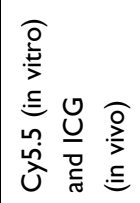 & $\underline{U}$ & $\underline{\underline{U}}$ & $\underline{U}$ & $\underline{\underline{U}}$ & $\underline{\underline{U}}$ & $\underline{\underline{U}}$ & $\underline{\underline{U}}$ \\
\hline 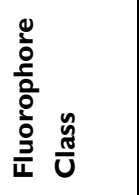 & 异 & & & & & & & & & & & & & \\
\hline
\end{tabular}


while imaging investigations of the IR825 loaded HSA NPs group indicated a strong fluorescence signal in the tumour after only $1 \mathrm{~h}$ post administration, reaching the maximum intensity $18 \mathrm{~h}$ post administration. Tables $2-4$ summarize the total of protein-based NPs loaded with NIR dyes discussed in section 3, the loaded fluorophore class, protein, size of the NPs and the types of cancer cells targeted for in vitro, in vivo and ex vivo fluorescence imaging.

\section{Clinical Trials Involving the Use of NIR Contrast Agents for Interventional Fluorescence Imaging of Cancer}

Despite the impressive number of newly developed NIR fluorescent nanoagents with promising outcomes in preclinical studies, ${ }^{116,117}$ most optical agents approved by FDA for fluorescent image-guided cancer surgery in clinical trials are free fluorescent agents (Table 5), typically with small hydrodynamic diameters, poor quantum yields and low photostability. IRDye $800 \mathrm{CW}$ is a cyanine dye (794 $\mathrm{nm}$ free IRDye $800 \mathrm{CW}$ emission maximum ${ }^{118}$ ) that received a lot of attention over the past couple of years as an NIR fluorescent agent in numerous clinical studies that evaluate the safety and diagnostic performance or aim to improve the detection of malignant lesions (even premalignant lesions in some cases) during interventional fluorescence imaging of different types of cancer, eg lung cancer (NCT04459065), head and neck cancer (NCT04511078; NCT01987375), oesophageal cancer and Barrett's Oesophagus (NCT02129933; NCT03877601), colorectal cancer (NCT04101292), pituitary carcinoma (NCT04212793) and brain tumour (NCT04085887).

The benefits of using fluorescence imaging for the early detection of oesophageal adenocarcinoma lesions and dysplasia are brought to light in the work of Nagengast et al $^{119}$ (NCT02129933), bevacizumab-IRDye $800 \mathrm{CW}$ being the drug of choice for 14 patients with Barrett's oesophagus. Before undergoing NIR fluorescence molecular endoscopy combined with endoscopic mucosal resection, the two compared administration routes of bevacizumab-IRDye $800 \mathrm{CW}$ to patients were systemic or topical tracer administration. Employing IRDye $800 \mathrm{CW}$ as a NIR fluorescent agent helped to identify typically challenging to distinguish and flat lesions, while the topical administration procedure enhanced the early detection of oesophageal adenocarcinoma lesions by $33 \%$, with respect to high-definition narrowband imaging and whitelight endoscopy. Moreover, the specimen obtained from the patients in the systemic administration of bevacizumab-IRDye $800 \mathrm{CW}$ approach group presented a tumour-to -background ratio (TBR) of 16.7. In the clinical study presented by Rosenthal et al $^{120}$ (NCT01987375), a total of 12 patients with various origins of head and neck cancer received different doses of cetuximab-IRDye $800 \mathrm{CW}$ (herein $2.5 \mathrm{mg} / \mathrm{m}^{2}, 25 \mathrm{mg} / \mathrm{m}^{2}$ and $62.5 \mathrm{mg} / \mathrm{m}^{2}$ ). In situ NIR fluorescence imaging of the cancerous tissue revealed a mean TBR of 4.3 for the patients in the $25 \mathrm{mg} / \mathrm{m}^{2}$ dose group, and a 5.2 mean TBR for the $62.5 \mathrm{mg} / \mathrm{m}^{2}$ dose group. The ex vivo NIR fluorescence imaging and pathology report of the obtained specimen were analysed and compared, confirming a good correlation between the fluorescence intensity of IRDye $800 \mathrm{CW}$ and tumour deposition (Figure 7).

The NIR fluorescent drug cRGDY-PEG-Cy5.5-C dots has been investigated for the first time in a clinical trial (NCT02106598) for patients with head and neck melanoma, breast cancer and colorectal cancer. The experimental Cy5.5 dye-labelled particle drug has been injected before or during the surgery around the primary tumour sites, aiming to assess their potential in discriminating between diseased and non-diseased sentinel lymph nodes. The quality of the fluorescence image contrast for the detection of sentinel lymph nodes was considered regarding their measured TBRs. Furthermore, the nodal specimens obtained after the finalization of the neck dissection have been scrutinized ex vivo to calculate the true and false-positive rates for NIR fluorescence cancer imaging and detection.

Another NIR drug, namely OTL-38 (796 nm free OTL38 emission maximum ${ }^{121}$ ) is a folate analogue ligand conjugated with an NIR indole cyanine-like green dye and has been studied in clinical trials as a fluorescent agent for the NIR image-guided surgery of cancer (lung cancer: NCT04241315, NCT02872701; ovarian cancer: NCT03180307). Hoogstins et al $^{121}$ reported the feasibility of the real-time interventional NIR fluorescence imaging procedure using intravenously infused OTL-38 as a fluorescent agent in 12 patients with ovarian cancer prior to the cytoreductive surgery. The NIR fluorescencebased imaging procedure enhanced the detection of malignant lesions beneath the targeted tissue surface (up to $8 \mathrm{~mm}$ ). During the whole procedure, the average measured TBR was constant, 4.4, and a sum total of 62 lesions were resected and confirmed via histopathology as true 
Table 4 Features and Use of Protein-Based NP Loaded with Cyanine - Heptamethine NIR Dyes for Interventional Fluorescence Imaging of Cancer in Preclinical Studies

\begin{tabular}{|c|c|c|c|c|c|c|c|c|}
\hline $\begin{array}{l}\text { Fluorophore } \\
\text { Class }\end{array}$ & $\begin{array}{l}\text { NIR } \\
\text { Fluorophore }\end{array}$ & $\begin{array}{l}\text { Emission } \\
\text { Maximum } \\
(\mathbf{n m})\end{array}$ & Protein & $\begin{array}{l}\text { Size } \\
(\mathrm{nm})\end{array}$ & $\begin{array}{l}\text { In vitro } \\
\text { NIR } \\
\text { Imaging } \\
\text { Cell } \\
\text { Line }\end{array}$ & $\begin{array}{l}\text { Preclinical in vivo (ex } \\
\text { vivo) NIR Imaging } \\
\text { Model }\end{array}$ & $\begin{array}{l}\text { Preclinical } \\
\text { in vivo (ex vivo) } \\
\text { Imaging Setup }\end{array}$ & Ref. \\
\hline \multirow[t]{8}{*}{$\begin{array}{l}\text { Cyanine - } \\
\text { Heptamethine }\end{array}$} & $\mathrm{CySCOOH}$ & 840 & HSA & 39 & - & $\begin{array}{l}\text { Athymic nude mice } \\
\text { subcutaneously injected } \\
\text { with MCF-7 cells }\end{array}$ & $\begin{array}{l}\text { Maestro in vivo } \\
\text { imaging system }\end{array}$ & [107] \\
\hline & IR780 iodide & $810^{109}$ & Transferrin & 65 & СТ26 & $\begin{array}{l}\text { Male Balb/c mice } \\
\text { subcutaneously injected } \\
\text { with CT26 cells }\end{array}$ & $\begin{array}{l}735 \mathrm{~nm} \\
\text { excitation; } \\
780-900 \mathrm{~nm} \\
\text { emission filter; } \\
\text { IVIS optical } \\
\text { imaging system }\end{array}$ & {$[110]$} \\
\hline & IR780 iodide & 810 & HSA & 6 & $\mathrm{~B} \times \mathrm{PC}-3$ & $\begin{array}{l}\text { Balb/c nude mice } \\
\text { subcutaneously injected } \\
\text { with BxPC-3 cells }\end{array}$ & $\begin{array}{l}745-785 \mathrm{~nm} \\
\text { emission filter; } \\
\text { Maestro in vivo } \\
\text { imaging system }\end{array}$ & [109] \\
\hline & $\begin{array}{l}\text { IR783 - } \\
\text { carboxylic } \\
\text { acid derivative }\end{array}$ & $818^{112}$ & HSA & 100 & $\begin{array}{l}\text { LSI74T, } \\
\text { HT29 and } \\
\text { SW480 }\end{array}$ & $\begin{array}{l}\text { Male Sabra rats } \\
\text { subcutaneously injected } \\
\text { with the carcinogen } \\
\text { dimethylhydrazine (DMH) } \\
\text { for colon polyp formation }\end{array}$ & $\begin{array}{l}780 \mathrm{~nm} \\
\text { excitation; } 800 \\
\mathrm{~nm} \text { emission } \\
\text { filter; Odyssey } \\
\text { infrared imaging } \\
\text { system; }\end{array}$ & {$\left[\begin{array}{lll}11 & 1\end{array}\right]$} \\
\hline & $\begin{array}{l}\text { IR783 - } \\
\text { carboxylic } \\
\text { acid derivative }\end{array}$ & 818 & HSA & 100 & - & $\begin{array}{l}\text { Nude mice with } \\
\text { orthotopic-tumours } \\
\text { originated from LSI74T and } \\
\text { HT29 cells }\end{array}$ & $\begin{array}{l}780 \mathrm{~nm} \\
\text { excitation; } 800 \\
\mathrm{~nm} \text { emission } \\
\text { filter; Odyssey } \\
\text { infrared imaging } \\
\text { system; }\end{array}$ & {$[112]$} \\
\hline & IR825 & - & HSA & 8 & $4 \mathrm{TI}$ & $\begin{array}{l}\text { Female nude mice } \\
\text { subcutaneously injected } \\
\text { with } 4 \mathrm{TI} \text { cells }\end{array}$ & $\begin{array}{l}\text { Maestro in vivo } \\
\text { imaging system }\end{array}$ & [114] \\
\hline & IR825 & - & HSA & 29 & A549 & $\begin{array}{l}\text { Nude mice subcutaneously } \\
\text { injected with A549 cells }\end{array}$ & - & [115] \\
\hline & IR825 & - & HSA & $5-10$ & $4 \mathrm{TI}$ & $\begin{array}{l}\text { Female nude mice and Balb/ } \\
\text { c mice subcutaneously } \\
\text { injected with } 4 \mathrm{TI} \text { cells }\end{array}$ & $\begin{array}{l}600 \mathrm{~nm} \\
\text { excitation; } \\
\text { Maestro in vivo } \\
\text { imaging system }\end{array}$ & {$\left[\begin{array}{lll}1 & 3\end{array}\right]$} \\
\hline
\end{tabular}

positives. Employing palpation and standard inspection methods alone, only $71 \%$ of the resected malignant lesions were detected.

Considering that ICG is one of the only two NIR fluorophores approved by the FDA for human use in a limited number of medical investigations, the imposing number of completed and ongoing interventional NIR fluorescence imaging clinical trials using ICG as the fluorescent agent is no surprise. Alone or in combination with other contrast agents, in recent years ICG has been the chosen NIR fluorescent agent in clinical studies for the intraoperative imaging and detection of a remarkable variety of cancer types, eg breast cancer (NCT03579979, NCT03619967, NCT02084784, NCT03735680), sentinel 


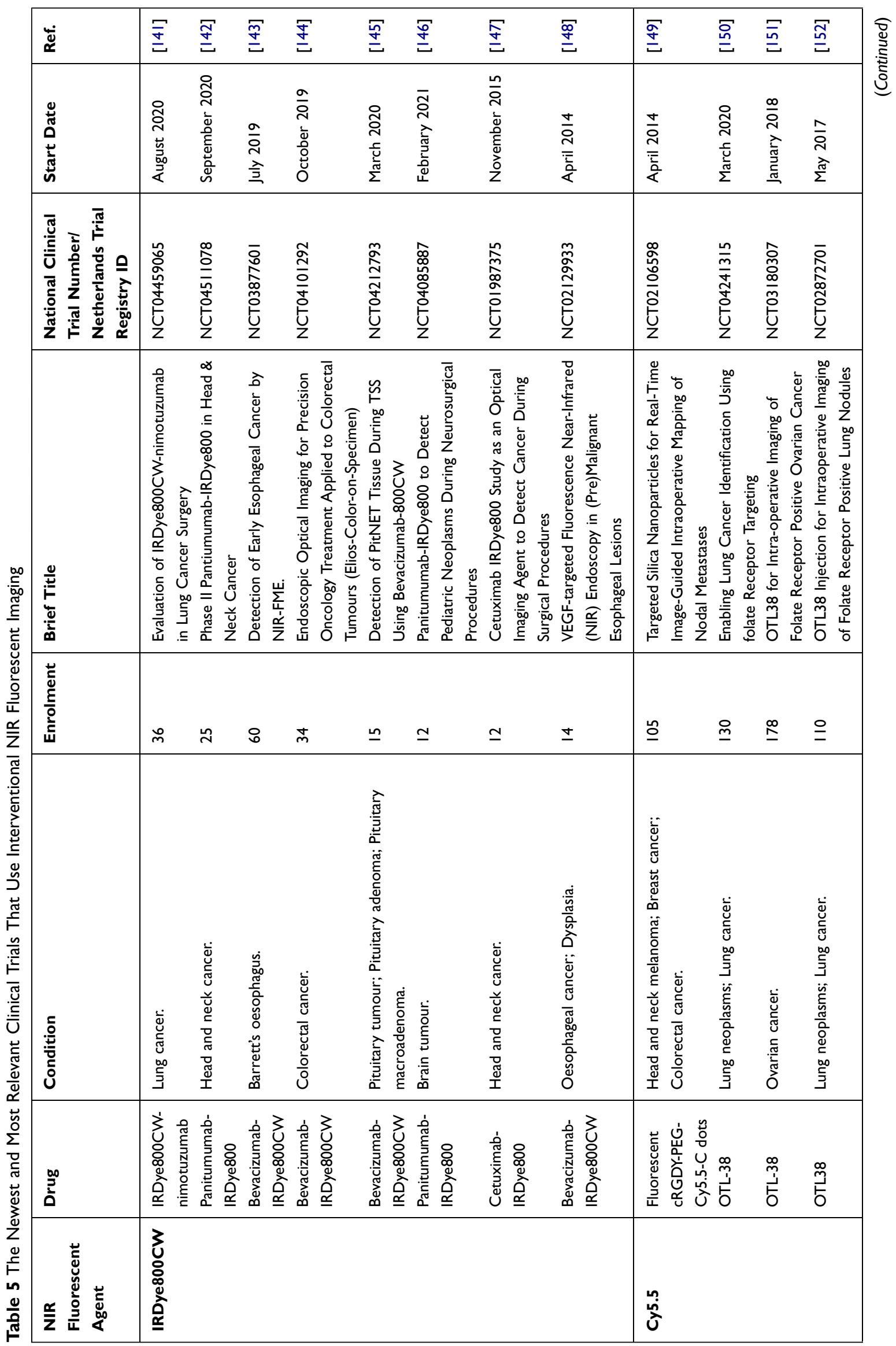




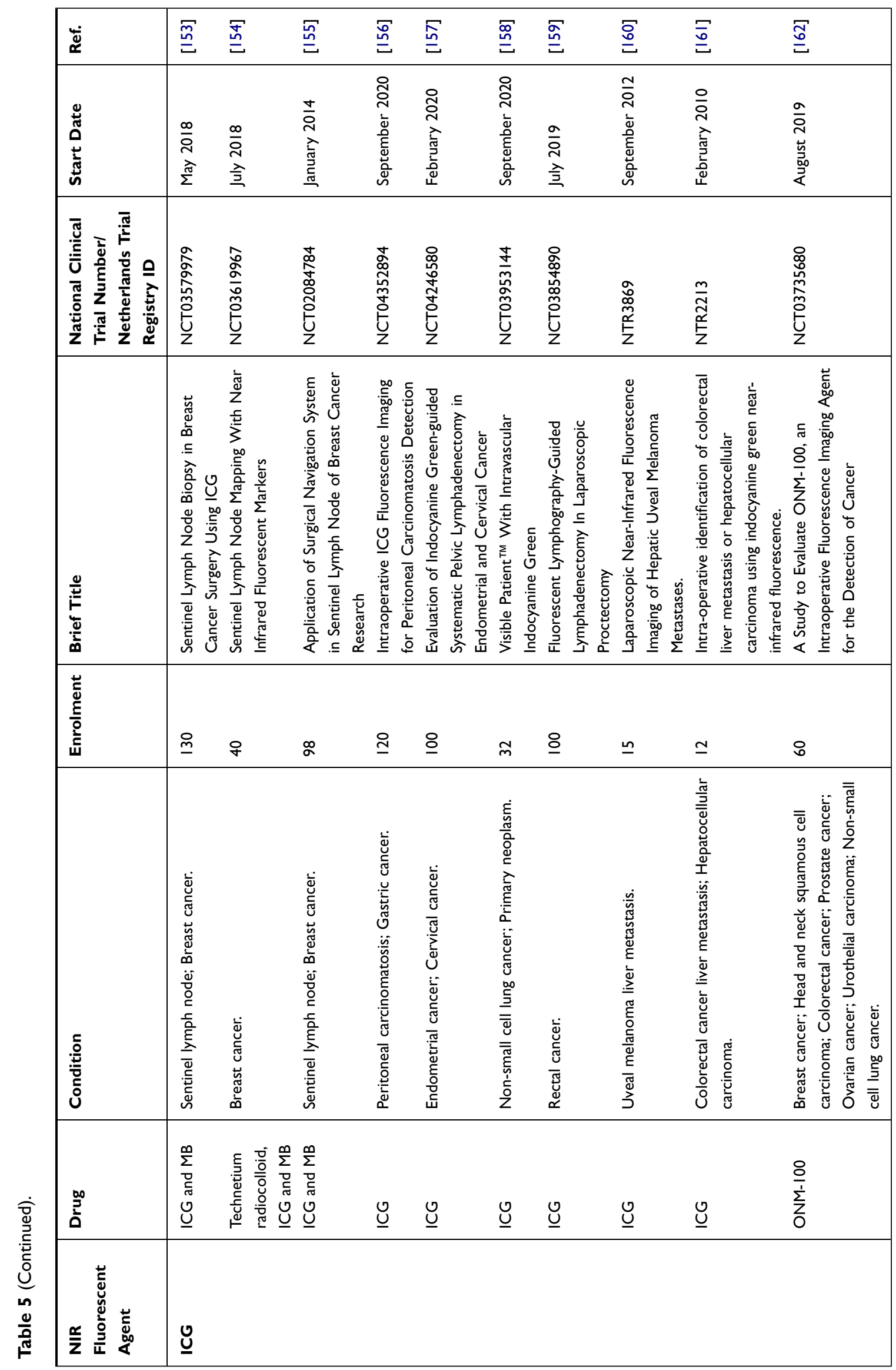



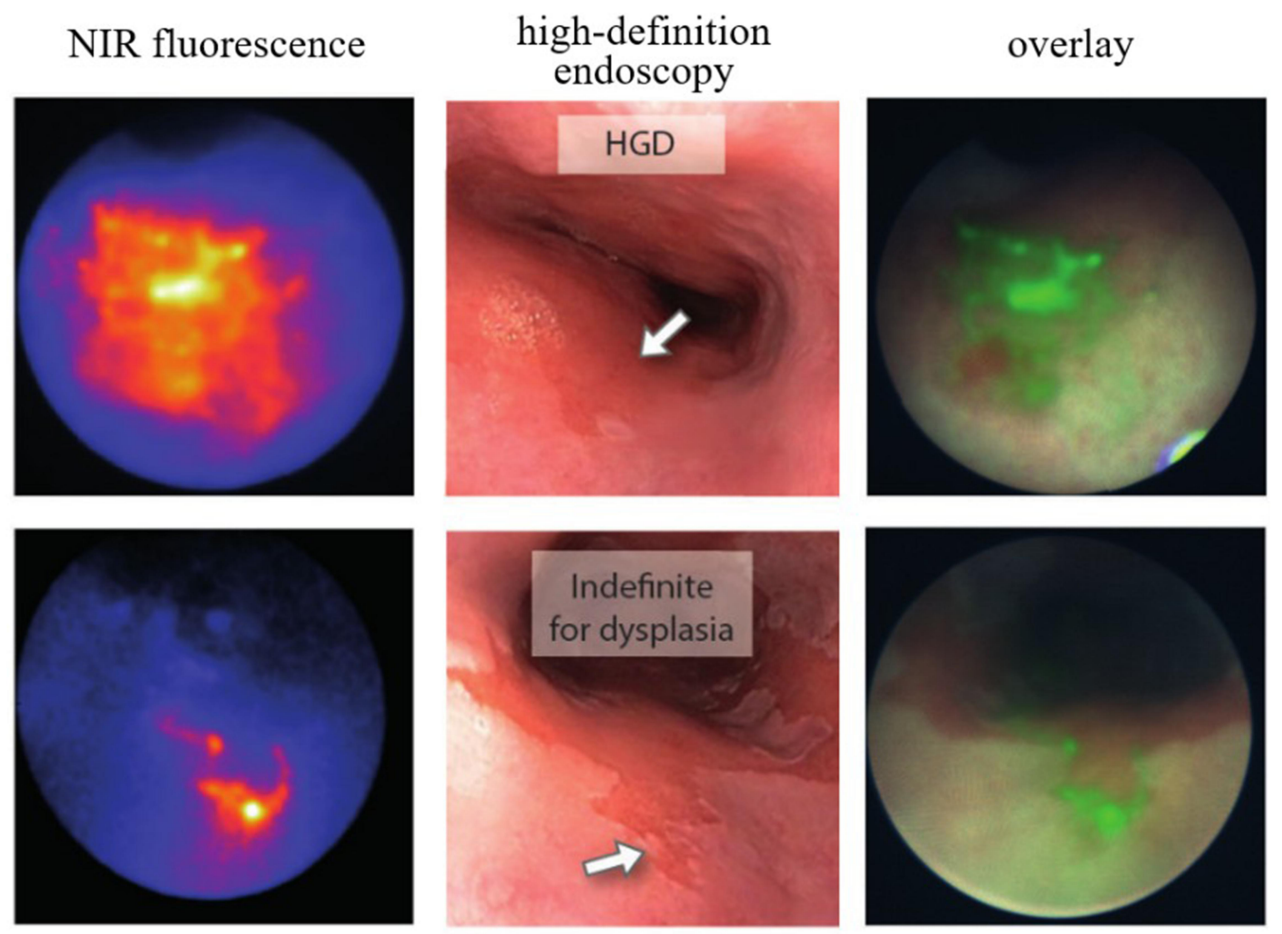

Figure 7 Real-time in situ NIR fluorescence imaging with bevacizumab-IRDye 800CW drug and high-definition endoscopy of oesophageal adenocarcinoma lesions. Dysplastic area missed during high-definition narrowband-imaging and white-light endoscopy inspection. Reproduced from Near-infrared fluorescence molecular endoscopy detects dysplastic oesophageal lesions using topical and systemic tracer of vascular endothelial growth factor A. Nagengast WB, Hartmans E, Garcia-Allende PB, et al. Gut. 68(1):7-10. Copyright 2019, with permission from BMJ Publishing Group Ltd. ${ }^{19}$

lymph nodes (NCT03579979, NCT02084784), peritoneal carcinomatosis and gastric cancer (NCT04352894), endometrial and cervical cancer (NCT04246580), non-small cell lung cancer (NCT03953144, NCT03735680), primary neoplasm (NCT03953144), rectal cancer (NCT03854890), uveal melanoma liver metastasis (NTR3869), colorectal cancer liver metastasis and hepatocellular carcinoma (NTR2213), head and neck squamous cell carcinoma, colorectal cancer, prostate cancer, ovarian cancer, and urothelial carcinoma (NCT03735680). In his work, He et al ${ }^{122}$ (NCT02084784) examines the safety and efficacy of using ICG for the real-time NIR fluorescence-guided sentinel lymph node biopsy of breast cancer in 98 female patients, as to the standard-of-care blue dye method, using $\mathrm{MB}$ staining. Patients received MB and ICG injections before the start of the surgery, offering the possibility to detect by percutaneous fluorescence imaging the lymphatic drainage and potential nodes prior to incision. Thus, the administration of ICG gave the patients the advantage of minimal incision, higher tissue penetration, enhanced detection rate ( $99 \%$ using the ICG method vs $92 \%$ for MB) and precise resection of the malignant tissue.
In pursuance of better retention of the drug of interest at the tumour site and higher quantum yields, a number of clinical trials in interventional NIR fluorescence imaging focus their attention on the binding of ICG with HSA molecules (ICG:HSA). In addition to the study presented by He et al, ${ }^{122}$ Troyan et al ${ }^{123}$ introduced the use of ICG: HSA as the fluorescent agent for the NIR fluorescent mapping of the sentinel lymph nodes during surgery, instead of using free ICG molecules. Due to the increased hydrodynamic diameter of the drug, as a result of the complex of the ICG dye and the $7 \mathrm{~nm}$ HSA protein molecules, the ICG:HSA method ensued in better NIR fluorescence contrast and enhanced retention of the fluorescent agent within the sentinel lymph nodes during realtime NIR image-guided surgery of cancer. In another clinical study, Verbeek et al $^{124}$ compared the use of free ICG vs ICG:HSA as optical agents for NIR fluorescent sentinel lymph node mapping (Figure 8) in 36 patients with vulvar cancer. The use of the ICG:HSA complex turned out to be $25 \%$ more efficient in detecting sentinel lymph nodes during real-time interventional NIR fluorescence imaging, as to the use of free ICG. 

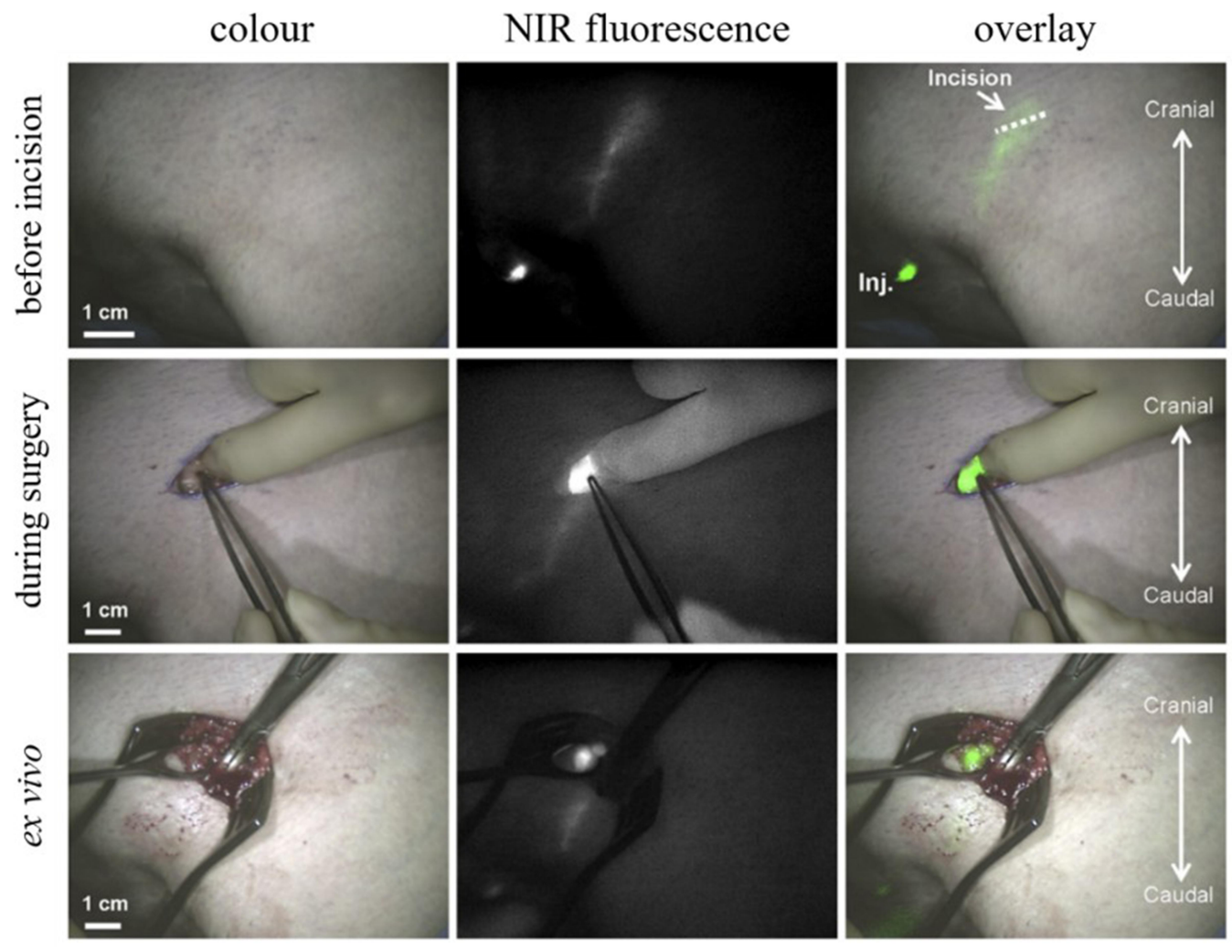

Figure 8 Real-time in situ NIR fluorescence imaging with ICG as the contrast agent of sentinel lymph nodes in vulvar cancer patients. Reproduced from Sentinel lymph node biopsy in vulvar cancer using combined radioactive and fluorescence guidance. Verbeek FPR, Tummers QRJG, Rietbergen DDD, et al. Int J Gynecol Cancer. 25:I086-1093. Copyright (2015), with permission from BMJ Publishing Gorup Ltd. ${ }^{124}$

At last, the emerging need of implementing in clinical trials a new generation of fluorescent agents for a better intratumoural internalization of the drug of interest and higher TBRs during surgery, based on the same NIR dyes or new ones, but loaded within nanostructures, such as NPs, is undeniable. Moreover, it is worth bearing in mind that out of over $60 \mathrm{NPs}$ that are now approved by the FDA in clinical trials, ${ }^{117}$ most of the NPs involved in clinical studies in oncology are organic NPs. ${ }^{125}$ Thus, with diameters in the optimal range (10-300 $\left.\mathrm{nm}^{105}\right)$ to undergo EPR-mediated passive targeting, a versatile surface chemistry offering the possibility of active targeting of the tumours, and countless preclinical studies proving their biocompatibility and efficiency as fluorescent agents, NIR fluorescent protein-based NPs exhibit bright potential as contrast agents for the realtime NIR fluorescence imaging of cancer in clinical trials.

\section{Conclusions}

The top-notch works summarized in this review acknowledge the versatility, biocompatibility and limitless functionalization possibility of protein-based NPs as the next generation of NIR imaging agents. The encapsulation or conjugation of NIR dyes to diverse protein-based NPs overcame the drawbacks of using free fluorophores for NIR imaging investigations (eg poor photostability and quantum yield, hydrophobicity and aggregation) resulting in impressive enhancement, 80 -fold in solution, of the fluorescence intensity of iodine-substituted squaraine dye when loaded onto protein-based NPs, in comparison with the free dye solution. In comparison to mice treated with free ICG, a 38-fold increase in the fluorescence signal was observed in the cancerous tissue of mice treated with protein-based NPs loaded with ICG. Thus, fluorescent protein-based NPs loaded with various NIR dyes present prolonged blood circulation time and enhanced accumulation in the tumour site, thanks to their enlarged size in comparison to free dye molecule and their surface chemistry and ability to bind with specific cancer ligands for an active targeting. The feasibility of NIR fluorescent protein-based NPs as contrast agents for the real-time interventional NIR fluorescence imaging of cancer in clinical trials was demonstrated by 
comparison to completed and ongoing clinical trials concerning fluorescent agents for cancer surgery, their biocompatibility being testified by a notable number of preclinical animal studies. Overall, it may be said that NIR dye loaded proteinbased NPs have the potential to be translated in the near future as imaging agents for real-time NIR fluorescence-guided cancer surgery.

\section{Acknowledgments}

This work was supported by a grant from the Ministry of Research and Innovation, CNCS-UEFISCDI, project number PN-III-P4-ID-PCCF-2016-0142, within PNCDI III.

\section{Disclosure}

The authors report no conflicts of interest in this work.

\section{References}

1. Copur MS. State of cancer research around the globe. Oncology (Williston Park, N Y). 2019;33(5):181-185.

2. Bray F, Ferlay J, Soerjomataram I, Siegel RL, Torre LA, Jemal A. Global cancer statistics 2018: GLOBOCAN estimates of incidence and mortality worldwide for 36 cancers in 185 countries. CA Cancer J Clin. 2018;68(6):394-424. doi:10.3322/caac.21492

3. Zhang RR, Schroeder AB, Grudzinski JJ, et al. Beyond the margins: real-time detection of cancer using targeted fluorophores. Nat Rev Clin Oncol. 2017;14(6):347-364. doi:10.1038/nrclinonc.2016.212

4. van Driel PBAA, van de Giessen M, Boonstra MC, et al. Characterization and evaluation of the artemis camera for fluorescence-guided cancer surgery. Mol Imaging Biol. 2015;17 (3):413-423. doi:10.1007/s11307-014-0799-z

5. Haque A, Faizi MSH Md, Rather JA, Khan MS. Next generation NIR fluorophores for tumor imaging and fluorescence-guided surgery: a review. Bioorg Med Chem. 2017;25(7):2017-2034. doi:10.1016/j.bmc.2017.02.061

6. Solomon SB, Silverman SG. Imaging in interventional oncology. Radiology. 2010;257(3):624-640. doi:10.1148/radiol.10081490

7. Paul NS, Ley S, Metser U. Optimal imaging protocols for lung cancer staging. Radiol Clin North Am. 2012;50:935-949.

8. de Boer E, Harlaar NJ, Taruttis A, et al. Optical innovations in surgery: optical innovations in surgery. Br J Surg. 2015;102(2): e56-e72. doi:10.1002/bjs.9713

9. Lakowicz JR. Principles of Fluorescence Spectroscopy. Boston, MA: Springer US; 1999

10. Sandra F, Khaliq NU, Sunna A, Care A. Developing protein-based nanoparticles as versatile delivery systems for cancer therapy and imaging. Nanomaterials. 2019;9(9):1329. doi:10.3390/nano9091329

11. Tarhini M, Greige-Gerges H, Elaissari A. Protein-based nanoparticles: from preparation to encapsulation of active molecules. Int $J$ Pharm. 2017;522(1-2):172-197. doi:10.1016/j. ijpharm.2017.01.067

12. Pansare VJ, Hejazi S, Faenza WJ, Prud'homme RK. Review of long-wavelength optical and NIR imaging materials: contrast agents, fluorophores, and multifunctional nano carriers. Chem Mater. 2012;24:812-827. doi:10.1021/cm2028367
13. Campu A, Focsan M, Lerouge F, et al. ICG-loaded gold nano-bipyramids with NIR activatable dual PTT-PDT therapeutic potential in melanoma cells. Colloids Surf B Biointerfaces. 2020;194:111213. doi:10.1016/j.colsurfb.2020.111213

14. van Leeuwen FWB, Hardwick JCH, van Erkel AR. Luminescence-based imaging approaches in the field of interventional molecular imaging. Radiology. 2015;276:12-29. doi:10.1148/radiol.2015132698

15. Chen C, Ou H, Liu R, Ding D. Regulating the photophysical property of organic/polymer optical agents for promoted cancer phototheranostics. Adv Mater. 2020;32:1806331. doi:10.1002/ adma.201806331

16. Ni X, Zhang X, Duan X, Zheng H-L, Xue X-S, Ding D. Nearinfrared afterglow luminescent aggregation-induced emission dots with ultrahigh tumor-to-liver signal ratio for promoted image-guided cancer. Surg Nano Lett. 2019;19:318-330. doi:10.1021/acs.nanolett.8b03936

17. Chen $\mathrm{C}, \mathrm{Ni} \mathrm{X}$, Jia S, et al. Massively evoking immunogenic cell death by focused mitochondrial oxidative stress using an AIE luminogen with a twisted molecular structure. Adv Mater. 2019;31:1904914. doi:10.1002/adma.201904914

18. Chen C, Ni X, Tian H, Liu Q, Guo D, Ding D. Calixarene-based supramolecular AIE dots with highly inhibited nonradiative decay and intersystem crossing for ultrasensitive fluorescence imageguided cancer surgery. Angew Chem Int Ed. 2020;59:10008-10012. doi:10.1002/anie.201916430

19. Yu J, Zhang X, Hao X, et al. Near-infrared fluorescence imaging using organic dye nanoparticles. Biomaterials. 2014;35 (10):3356-3364. doi:10.1016/j.biomaterials.2014.01.004

20. Luo S, Zhang E, Su Y, Cheng T, Shi C. A review of NIR dyes in cancer targeting and imaging. Biomaterials. 2011;32 (29):7127-7138. doi:10.1016/j.biomaterials.2011.06.024

21. Ptaszek M. Rational design of fluorophores for in vivo applications. Prog Mol Biol Transl Sci. 2013;113:59-108.

22. Demchenko AP, Callis PR. Advanced Fluorescence Reporters in Chemistry and Biology I: Fundamentals and Molecular Design. Heidelberg, New York: Springer; 2010.

23. Voswinckel P. A constant source of surprises: acute porphyria. Two cases reported by hippocrates and sigmund freud. Hist Psychiatry. 1990;1:159-168. doi:10.1177/0957154X9000100201

24. Buschow KHJ. Encyclopedia of Materials: Science and Technology. Amsterdam; New York: Elsevier; 2001.

25. Anon. Infrared Absorbing Dyes. New York: Place of publication not identified: Springer-Verlag; 2013.

26. Nalwa HS. Supramolecular Photosensitive and Electroactive Materials. San Diego, CA: Academic Press; 2001.

27. Sun W, Guo S, Hu C, Fan J, Peng X. Recent development of chemosensors based on cyanine platforms. Chem Rev. 2016;116:7768-7817. doi:10.1021/acs.chemrev.6b00001

28. Chu L, Wang S, Li K, Xi W, Zhao X, Qian J. Biocompatible near-infrared fluorescent nanoparticles for macro and microscopic in vivo functional bioimaging. Biomed Opt Express. 2014;5:4076. doi:10.1364/BOE.5.004076

29. Madamsetty VS, Mukherjee A, Mukherjee S. Recent trends of the bio-inspired nanoparticles in cancer theranostics. Front Pharmacol. 2019;10:1264. doi:10.3389/fphar.2019.01264

30. Wang EC, Wang AZ. Nanoparticles and their applications in cell and molecular biology. Integr Biol. 2014;6:9-26. doi:10.1039/ c3ib40165k

31. Duclairoir C, Nakache E, Marchais H, Orecchioni A-M. Formation of gliadin nanoparticles: influence of the solubility parameter of the protein solvent. Colloid Polym Sci. 1998;276:321-327. doi:10.1007/s003960050246

32. Pathak Y, Thassu D. Drug Delivery Nanoparticles Formulation and Characterization. New York: Informa Healthcare; 2009. 
33. Duclairoir C, Orecchioni A-M, Depraetere P, Osterstock F, Nakache E. Evaluation of gliadins nanoparticles as drug delivery systems: a study of three different drugs. Int $J$ Pharm. 2003;253:133-144. doi:10.1016/S0378-5173(02)00701-9

34. Irache J. Optimization and in vitro stability of legumin nanoparticles obtained by a coacervation method. Int J Pharm. 1995;126 (1-2):103-109. doi:10.1016/0378-5173(95)04103-6

35. Podaralla S, Perumal O. Preparation of zein nanoparticles by $\mathrm{pH}$ controlled nanoprecipitation. j Biomed Nanotechnol. 2010;6:312-317. doi:10.1166/jbn.2010.1137

36. Torres-Giner S, Martinez-Abad A, Ocio MJ, Lagaron JM. Stabilization of a nutraceutical omega-3 fatty acid by encapsulation in ultrathin electrosprayed zein prolamine. J Food Sci. 2010;75(6):N69-N79. doi:10.1111/j.1750-3841.2010.01678.x

37. Wang H, Zhu W, Huang Y, Li Z, Jiang Y, Xie Q. Facile encapsulation of hydroxycamptothecin nanocrystals into zein-based nanocomplexes for active targeting in drug delivery and cell imaging. Acta Biomater. 2017;61:88-100. doi:10.1016/j.actbio.2017.04.017

38. Jain SK, Gupta Y, Jain A, Saxena AR, Khare P, Jain A. Mannosylated gelatin nanoparticles bearing an anti-HIV drug didanosine for site-specific delivery. Nanomedicine. 2008;4 (1):41-48. doi:10.1016/j.nano.2007.11.004

39. Gupta AK, Gupta M, Yarwood SJ, Curtis ASG. Effect of cellular uptake of gelatin nanoparticles on adhesion, morphology and cytoskeleton organisation of human fibroblasts. $J$ Control Release. 2004;95(2):197-207. doi:10.1016/j.jconrel.2003.11.006

40. Bajpai AK, Choubey J. Design of gelatin nanoparticles as swelling controlled delivery system for chloroquine phosphate. J Mater Sci Mater Med. 2006;17:345-358. doi:10.1007/s10856006-8235-9

41. Lee EJ, Khan SA, Park JK, Lim K-H. Studies on the characteristics of drug-loaded gelatin nanoparticles prepared by nanoprecipitation. Bioprocess Biosyst Eng. 2012;35(1-2):297-307. doi:10.1007/s00449-011-0591-2

42. Vandervoort J, Ludwig A. Preparation and evaluation of drug-loaded gelatin nanoparticles for topical ophthalmic use. Eur J Pharm Biopharm. 2004;57(2):251-261. doi:10.1016/ S0939-6411(03)00187-5

43. Kundu J, Chung Y-I, Kim YH, Tae G, Kundu SC. Silk fibroin nanoparticles for cellular uptake and control release. Int J Pharm. 2010;388(1-2):242-250. doi:10.1016/j.ijpharm.2009.12.052

44. Mandal BB, Kundu SC. Self-assembled silk sericin/poloxamer nanoparticles as nanocarriers of hydrophobic and hydrophilic drugs for targeted delivery. Nanotechnology. 2009;20 (35):355101. doi:10.1088/0957-4484/20/35/355101

45. Lammel AS, Hu X, Park S-H, Kaplan DL, Scheibel TR. Controlling silk fibroin particle features for drug delivery. Biomaterials. 2010;31(16):4583-4591. doi:10.1016/j. biomaterials.2010.02.024

46. Khalid A, Mitropoulos AN, Marelli B, Tomljenovic-Hanic S, Omenetto FG. Doxorubicin loaded nanodiamond-silk spheres for fluorescence tracking and controlled drug release. Biomed Opt Express. 2016;7(1):132. doi:10.1364/BOE.7.000132

47. Penalva R, Esparza I, Agüeros M, Gonzalez-Navarro CJ, Gonzalez-Ferrero C, Irache JM. Casein nanoparticles as carriers for the oral delivery of folic acid. Food Hydrocoll. 2015;44:399-406. doi:10.1016/j.foodhyd.2014.10.004

48. Elzoghby A, Helmy mw, Samy WM, Elgindy NA. Novel ionically crosslinked casein nanoparticles for flutamide delivery: formulation, characterization, and in vivo pharmacokinetics. IJN. 2013;8:1721.

49. Pan K, Luo Y, Gan Y, Baek SJ, Zhong Q. pH-driven encapsulation of curcumin in self-assembled casein nanoparticles for enhanced dispersibility and bioactivity. Soft Matter. 2014;10 (35):6820. doi:10.1039/C4SM00239C
50. López-Rubio A, Lagaron JM. Whey protein capsules obtained through electrospraying for the encapsulation of bioactives. Innov Food Sci Emerg Technol. 2012;13:200-206. doi:10.1016/j. ifset.2011.10.012

51. Worsdorfer B, Woycechowsky KJ, Hilvert D. Directed evolution of a protein container. Science. 2011;331(6017):589-592. doi:10.1126/science.1199081

52. Sun Q, Chen Q, Blackstock D, Chen W. Post-translational modification of bionanoparticles as a modular platform for biosensor assembly. ACS Nano. 2015;9(8):8554-8561. doi:10.1021/ acsnano. 5 b03688

53. Izard $\mathrm{T}$, Aevarsson $\mathrm{A}$, Allen $\mathrm{MD}$, et al. Principles of quasi-equivalence and euclidean geometry govern the assembly of cubic and dodecahedral cores of pyruvate dehydrogenase complexes. Proc Natl Acad Sci. 1999;96(4):1240-1245. doi:10.1073/pnas.96.4.1240

54. Lee EJ, Lee NK, Kim I-S. Bioengineered protein-based nanocage for drug delivery. Adv Drug Deliv Rev. 2016;106:157-171.

55. Bhushan B, Kumar SU, Matai I, Sachdev A, Dubey P, Gopinath P. Ferritin nanocages: a novel platform for biomedical applications. J Biomed Nanotechnol. 2014;10(10):2950-2976. doi:10.1166/ jbn.2014.1980

56. Zhen Z, Tang W, Chen H, et al. RGD-Modified apoferritin nanoparticles for efficient drug delivery to tumors. ACS Nano. 2013;7 (6):4830-4837. doi:10.1021/nn305791q

57. Kanwar JR, Kamalapuram SK, Krishnakumar S, Kanwar RK. Multimodal iron oxide ( $\mathrm{Fe}_{3} \mathrm{O}_{4}$ )-saturated lactoferrin nanocapsules as nanotheranostics for real-time imaging and breast cancer therapy of claudin-low, triple-negative (ER ${ }^{-} / \mathrm{PR}{ }^{-} / \mathrm{HER} 2{ }^{-}$). Nanomedicine. 2016;11:249-268. doi:10.2217/nnm.15.199

58. Chen M-L, He Y-J, Chen X-W, Wang J-H. Quantum-dotconjugated graphene as a probe for simultaneous cancer-targeted fluorescent imaging, tracking, and monitoring drug delivery. Bioconjug Chem. 2013;24:387-397. doi:10.1021/bc3004809

59. Wang D, Li Y, Tian Z, Cao R, Yang B. Transferrin-conjugated nanodiamond as an intracellular transporter of chemotherapeutic drug and targeting therapy for cancer cells. Ther Deliv. 2014;5:511-524. doi:10.4155/tde.14.17

60. Sonali SRP, Singh N, Sharma G, et al. Transferrin liposomes of docetaxel for brain-targeted cancer applications: formulation and brain theranostics. Drug Deliv. 2016;23:1261-1271. doi:10.3109/ 10717544.2016.1162878

61. Wang D, Zhu L, Pu Y, Wang J-X, Chen J-F, Dai L. Transferrincoated magnetic upconversion nanoparticles for efficient photodynamic therapy with near-infrared irradiation and luminescence bioimaging. Nanoscale. 2017;9:11214-11221. doi:10.1039/ C7NR03019C

62. Hou L, Shan X, Hao L, Feng Q, Zhang Z. Copper sulfide nanoparticle-based localized drug delivery system as an effective cancer synergistic treatment and theranostic platform. Acta Biomater. 2017;54:307-320. doi:10.1016/j.actbio.2017.03.005

63. Gradishar WJ. Albumin-bound paclitaxel: a next-generation taxane. Expert Opin Pharmacother. 2006;7:1041-1053. doi:10.1517/14656566.7.8.1041

64. An -F-F, Zhang X-H. Strategies for preparing albumin-based nanoparticles for multifunctional bioimaging and drug delivery. Theranostics. 2017;7:3667-3689. doi:10.7150/thno.19365

65. Yu X, Zhu W, Di Y, et al. Triple-functional albumin-based nanoparticles for combined chemotherapy and photodynamic therapy of pancreatic cancer with lymphatic metastases. IJN. 2017;12:6771-6785. doi:10.2147/IJN.S131295

66. Gao L, Fan K, Yan X. Iron oxide nanozyme: a multifunctional enzyme mimetic for biomedical applications. Theranostics. 2017;7:3207-3227. doi:10.7150/thno.19738 
67. Peer D, Karp JM, Hong S, Farokhzad OC, Margalit R, Langer R. Nanocarriers as an emerging platform for cancer therapy. Nat Nanotech. 2007;2:751-760. doi:10.1038/nnano.2007.387

68. Cardinale D, Carette N, Michon T. Virus scaffolds as enzyme nano-carriers. Trends Biotechnol. 2012;30:369-376. doi:10.1016/ j.tibtech.2012.04.001

69. Patterson DP, Prevelige PE, Douglas T. Nanoreactors by programmed enzyme encapsulation inside the capsid of the bacteriophage P22. ACS Nano. 2012;6:5000-5009. doi:10.1021/nn300545z

70. Koudelka KJ, Pitek AS, Manchester M, Steinmetz NF. Virusbased nanoparticles as versatile nanomachines. Annu Rev Virol. 2015;2:379-401. doi:10.1146/annurev-virology-100114-055141

71. Plummer EM, Manchester M. Viral nanoparticles and virus-like particles: platforms for contemporary vaccine design: platforms for contemporary vaccine design WIREs. Nanomed Nanobiotechnol. 2011;3:174-196. doi:10.1002/wnan.119

72. Yildiz I, Shukla S, Steinmetz NF. Applications of viral nanoparticles in medicine. Curr Opin Biotechnol. 2011;22:901-908. doi:10.1016/j.copbio.2011.04.020

73. Elzoghby AO, Elgohary MM, Kamel NM. Implications of proteinand peptide-based nanoparticles as potential vehicles for anticancer drugs. Adv Protein Chem Struct Biol. 2015;98:169-221.

74. Freeman HJ. Celiac Disease. In: Reference Module in Biomedical Sciences. Elsevier; 2017:B9780128012383000000. Available from: ht tps:// inkinghub.elsevier.com/retrieve/pii/ B9780128012383000532. Accessed March 04, 2021.

75. Gou Y, Miao D, Zhou M, Wang L, Zhou H, Su G. Bio-inspired protein-based nanoformulations for cancer theranostics. Front Pharmacol. 2018;9:421. doi:10.3389/fphar.2018.00421

76. Benjakul S, Kittiphattanabawon P. Gelatin Encyclopedia of Food Chemistry. Elsevier; 2019:121-127.

77. Smith AM, Moxon S, Morris GA. Biopolymers as Wound Healing Materials Wound Healing Biomaterials. Elsevier; 2016:261-287.

78. Alihosseini F. Plant-Based Compounds for Antimicrobial Textiles Antimicrobial Textiles. Elsevier; 2016:155-195.

79. Salama BM, Helmy WA, Ragab TIM, Ali MM, Taie HAA, Esawy MA. Characterization of a new efficient low molecular weight Bacillus subtilis $\mathrm{NRC}_{16}$ levansucrase and its levan. $J$ Basic Microbiol. 2019;59:1004-1015. doi:10.1002/jobm.201900170

80. Chen Q, Cheng M, Wang Y, et al. A simple method of catalase purification for the undergraduate experimental course. Mol Med Rep. 2015;11:1340-1343. doi:10.3892/mmr.2014.2806

81. Pundir CS. Introduction to Enzyme and Nanotechnology Enzyme Nanoparticles. Elsevier; 2015:1-7.

82. Raeeszadeh-Sarmazdeh M, Hartzell E, Price JV, Chen W. Protein nanoparticles as multifunctional biocatalysts and health assessment sensors. Curr Opin Chem Eng. 2016;13:109-118. doi:10.1016/j.coche.2016.08.016

83. Pundir CS. Applications of Enzyme Nanoparticles Enzyme Nanoparticles. Elsevier; 2015:43-60.

84. Gao F-P, Lin Y-X, Li -L-L, et al. Supramolecular adducts of squaraine and protein for noninvasive tumor imaging and photothermal therapy in vivo. Biomaterials. 2014;35:1004-1014. doi:10.1016/j.biomaterials.2013.10.039

85. Battogtokh G, Ko YT. Graphene oxide-incorporated pH-responsive folate-albumin-photosensitizer nanocomplex as image-guided dual therapeutics. $J$ Control Release. 2016;234:10-20. doi:10.1016/j.jconrel.2016.05.007

86. Chen Q, Wang X, Wang C, Feng L, Li Y, Liu Z. Drug-induced self-assembly of modified albumins as nano-theranostics for tumor-targeted combination therapy. ACS Nano. 2015;9:5223-5233. doi:10.1021/acsnano.5b00640

87. Hu D, Sheng Z, Gao G, et al. Activatable albumin-photosensitizer nanoassemblies for triple-modal imaging and thermal-modulated photodynamic therapy of cancer. Biomaterials. 2016;93:10-19. doi:10.1016/j.biomaterials.2016.03.037
88. Dong C, Liu Z, Wang S, et al. A protein-polymer bioconjugatecoated upconversion nanosystem for simultaneous tumor cell imaging, photodynamic therapy, and chemotherapy. ACS Appl Mater Interfaces. 2016;8(48):32688-32698. doi:10.1021/ acsami.6b11803

89. Aldred E. Scientific Tests Pharmacology. Elsevier; 2009:331-341.

90. Zhen Z, Tang W, Guo C, et al. Ferritin nanocages to encapsulate and deliver photosensitizers for efficient photodynamic therapy against cancer. ACS Nano. 2013;7(8):6988-6996. doi:10.1021/ $\mathrm{nn} 402199 \mathrm{~g}$

91. Richardson DR, Ponka P. The molecular mechanisms of the metabolism and transport of iron in normal and neoplastic cells. Biochim Biophys Acta. 1997;1331(1):1-40. doi:10.1016/S03044157(96)00014-7

92. Kang CS, Ren S, Sun X, Chong H-S. Theranostic polyaminocarboxylate-cyanine-transferrin conjugate for anticancer therapy and near-infrared optical imaging. Chem Med Chem. 2016;11(19):2188-2193. doi:10.1002/cmdc.201600072

93. Peng H, Tang J, Zheng R, et al. Nuclear-targeted multifunctional magnetic nanoparticles for photothermal therapy. Adv Healthcare Mater. 2017;6(7):1601289. doi:10.1002/adhm.201601289

94. Zhu M, Sheng Z, Jia Y, et al. Indocyanine green-holo-transferrin nanoassemblies for tumor-targeted dual-modal imaging and photothermal therapy of glioma. ACS Appl Mater Interfaces. 2017;9:39249-39258. doi:10.1021/acsami.7b14076

95. Wei W, Zhang Y, Shao H, Hu X. Determination of molecular weight of silk fibroin by non-gel sieving capillary electrophoresis. J AOAC Int. 2010;93:1143-1147. doi:10.1093/jaoac/93.4.1143

96. Mottaghitalab F, Farokhi M, Shokrgozar MA, Atyabi F, Hosseinkhani H. Silk fibroin nanoparticle as a novel drug delivery system. J Control Release. 2015;206:161-176.

97. Liu B, Wu P, Sha H, et al. Anti-EGFR-iRGD recombinant protein conjugated silk fibroin nanoparticles for enhanced tumor targeting and antitumor efficiency. OTT. 2016;3153. doi:10.2147/OTT. S100678

98. Hu H, Zhang Y, Shukla S, Gu Y, Yu X, Steinmetz NF. Dysprosium-modified tobacco mosaic virus nanoparticles for ultra-high-field magnetic resonance and near-infrared fluorescence imaging of prostate cancer. ACS Nano. 2017;11:9249-9258. doi:10.1021/acsnano.7b04472

99. Li X, Mu J, Liu F, et al. Human transport protein carrier for controlled photoactivation of antitumor prodrug and real-time intracellular tumor imaging. Bioconjug Chem. 2015;26:955-961. doi:10.1021/acs.bioconjchem.5b00170

100. Chen S, Yu G, Zhang B, Wang Y, Zhang N, Chen Y. Human serum albumin (HSA) coated liposomal indocyanine green for in vivo tumor imaging. RSC $A d v$. 2016;6(18):15220-15225. doi:10.1039/C5RA25129J

101. Xu L, Wang S-B, Xu C, et al. Multifunctional albumin-based delivery system generated by programmed assembly for tumor-targeted multimodal therapy and imaging. ACS Appl Mater Interfaces. 2019;11:38385-38394. doi:10.1021/acsami.9b11263

102. Sahu A, Lee JH, Lee HG, Jeong YY, Tae G. Prussian blue/serum albumin/indocyanine green as a multifunctional nanotheranostic agent for bimodal imaging guided laser mediated combinatorial phototherapy. J Control Release. 2016;236:90-99. doi:10.1016/j. jconrel.2016.06.031

103. Chen Q, Liang C, Wang C, Liu Z. An imagable and photothermal "abraxane-like" nanodrug for combination cancer therapy to treat subcutaneous and metastatic breast tumors. Adv Mater. 2015;27:903-910. doi:10.1002/adma.201404308

104. Sheng $\mathrm{Z}, \mathrm{Hu} \mathrm{D}$, Zheng $\mathrm{M}$, et al. Smart human serum albumin-indocyanine green nanoparticles generated by programmed assembly for dual-modal imaging-guided cancer synergistic phototherapy. ACS Nano. 2014;8:12310-12322. doi:10.1021/nn5062386 
105. Borlan R, Tatar A-S, Soritau O, et al. Design of fluorophore-loaded human serum albumin nanoparticles for specific targeting of NIH: OVCAR3 ovarian cancer cells. Nanotechnology. 2020;31:315102. doi:10.1088/1361-6528/ab8b90

106. Yang H, Liu Z, Li X, Zhang Z, Chen D, Lian H. Artesunate-loaded and near-infrared dye-conjugated albumin nanoparticles as high-efficiency tumor-targeted photo-chemo theranostic agent. Nanoscale Res Lett. 2018;13:319. doi:10.1186/s11671-018-2700-5

107. Rong P, Huang P, Liu Z, et al. Protein-based photothermal theranostics for imaging-guided cancer therapy. Nanoscale. 2015;7 (39):16330-16336. doi:10.1039/C5NR04428F

108. Nagy-Simon T, Potara M, Craciun A-M, Licarete E, Astilean S. IR780-dye loaded gold nanoparticles as new near infrared activatable nanotheranostic agents for simultaneous photodynamic and photothermal therapy and intracellular tracking by surface enhanced resonant Raman scattering imaging. $J$ Colloid Interface Sci. 2018;517:239-250. doi:10.1016/j. jcis.2018.02.007

109. Han H, Wang J, Chen T, Yin L, Jin Q, Ji J. Enzyme-sensitive gemcitabine conjugated albumin nanoparticles as a versatile theranostic nanoplatform for pancreatic cancer treatment. J Colloid Interface Sci. 2017;507:217-224. doi:10.1016/j.jcis.2017.07.047

110. Wang K, Zhang Y, Wang J, et al. Self-assembled IR780-loaded transferrin nanoparticles as an imaging, targeting and PDT/PTT agent for cancer therapy. Sci Rep. 2016;6(1):27421. doi:10.1038/ srep 27421

111. Cohen S, Pellach M, Kam Y, et al. Synthesis and characterization of near IR fluorescent albumin nanoparticles for optical detection of colon cancer. Mat Sci Eng C. 2013;33(2):923-931. doi:10.1016/j.msec.2012.11.022

112. Cohen S, Margel S. Engineering of near IR fluorescent albumin nanoparticles for in vivo detection of colon cancer. J Nanobiotechnol. 2012;10(1):36. doi:10.1186/1477-3155-10-36

113. Chen Q, Wang C, Zhan Z, et al. Near-infrared dye bound albumin with separated imaging and therapy wavelength channels for imaging-guided photothermal therapy. Biomaterials. 2014;35(28):8206-8214. doi:10.1016/j.biomaterials.2014. 06.013

114. Chen Q, Liang C, Wang X, He J, Li Y, Liu Z. An albumin-based theranostic nano-agent for dual-modal imaging guided photothermal therapy to inhibit lymphatic metastasis of cancer post surgery. Biomaterials. 2014;35(34):9355-9362. doi:10.1016/j. biomaterials.2014.07.062

115. Gao G, Jiang Y, Sun W, et al. Molecular targeting-mediated mild-temperature photothermal therapy with a smart albumin-based nanodrug. Small. 2019;1900501. doi:10.1002/ smll.201900501

116. Hong G, Antaris AL, Dai H. Near-infrared fluorophores for biomedical imaging. Nat Biomed Eng. 2017;1(1):0010. doi:10.1038/s41551-016-0010

117. Hu Z, Chen W-H, Tian J, Cheng Z. NIRF nanoprobes for cancer molecular imaging: approaching clinic. Trends Mol Med. 2020;26 (5):469-482. doi:10.1016/j.molmed.2020.02.003

118. LI-COR. IRDye infrared fluorescent dyes deliver enhanced sensitivity. Available from: https://www.licor.com/bio/reagents/ irdye-infrared-dyes. Accessed March 04, 2021.

119. Nagengast WB, Hartmans E, Garcia-Allende PB, et al. Nearinfrared fluorescence molecular endoscopy detects dysplastic oesophageal lesions using topical and systemic tracer of vascular endothelial growth factor A. Gut. 2019;68(1):7-10. doi:10.1136/ gutjnl-2017-314953

120. Rosenthal EL, Warram JM, de Boer E, et al. Safety and tumor specificity of cetuximab-IRDye800 for surgical navigation in head and neck cancer. Clin Cancer Res. 2015;21 (16):3658-3666. doi:10.1158/1078-0432.CCR-14-3284
121. Hoogstins CES, Tummers QRJG, Gaarenstroom KN, et al. A novel tumor-specific agent for intraoperative near-infrared fluorescence imaging: a translational study in healthy volunteers and patients with ovarian cancer. Clin Cancer Res. 2016;22:2929-2938. doi:10.1158/1078-0432.CCR-15-2640

122. He K, Chi C, Kou D, et al. Comparison between the indocyanine green fluorescence and blue dye methods for sentinel lymph node biopsy using novel fluorescence image-guided resection equipment in different types of hospitals. Transl Res. 2016;178:74-80. doi:10.1016/j.trsl.2016.07.010

123. Troyan SL, Kianzad V, Gibbs-Strauss SL, et al. The FLARE ${ }^{\mathrm{TM}}$ intraoperative near-infrared fluorescence imaging system: a first-in-human clinical trial in breast cancer sentinel lymph node mapping. Ann Surg Oncol. 2009;16:2943-2952. doi:10.1245/ s10434-009-0594-2

124. Verbeek FPR, Tummers QRJG, Rietbergen DDD, et al. Sentinel lymph node biopsy in vulvar cancer using combined radioactive and fluorescence guidance. Int $J$ Gynecol Cancer. 2015;25:1086-1093. doi:10.1097/IGC.0000000000000419

125. Egloff-Juras C, Bezdetnaya L, Dolivet G, Lassalle H-P. NIR fluorescence-guided tumor surgery: new strategies for the use of indocyanine green. IJN. 2019;14:7823-7838. doi:10.2147/IJN. S207486

126. Mayerhöffer U, Fimmel B, Würthner F. Bright near-infrared fluorophores based on squaraines by unexpected halogen effects. Angew Chem Int Ed. 2012;51(1):164-167. doi:10.1002/ anie. 201107176

127. Peng X, Du J, Fan J, et al. A selective fluorescent sensor for imaging $\mathrm{Cd}^{2+}$ in living cells. $J$ Am Chem Soc. 2007;129:1500-1501. doi:10.1021/ja0643319

128. Ni Y, Wu J. Far-red and near infrared BODIPY dyes: synthesis and applications for fluorescent $\mathrm{pH}$ probes and bio-imaging. Org Biomol Chem. 2014;12:3774. doi:10.1039/c3ob42554a

129. Nyman ES, Hynninen PH. Research advances in the use of tetrapyrrolic photosensitizers for photodynamic therapy. $J$ Photochem Photobiol B. 2004;73:1-28. doi:10.1016/j. jphotobiol.2003.10.002

130. Kay A, Humphry-Baker R, Graetzel M. Artificial photosynthesis. 2. Investigations on the mechanism of photosensitization of nanocrystalline $\mathrm{TiO} 2$ solar cells by chlorophyll derivatives. J Phys Chem. 1994;98:952-959. doi:10.1021/j100054a035

131. Whalley M. Conjugated macrocycles. Part XXXII. Absorption spectra of tetrazaporphins and phthalocyanines. Formation of pyridine salts. J Chem Soc. 1961;182:866. doi:10.1039/ jr9610000866

132. Seybold PG, Gouterman M. Porphyrins. J Mol Spectrosc. 1969;31:1-13. doi:10.1016/0022-2852(69)90335-X

133. omlc.org. Zinc phthalocyanine, [ZnPc]. Available from: https:// omlc.org/spectra/PhotochemCAD/html/026.html. Accessed February 23, 2021.

134. Dai Z. Advances in Nanotheranostics I. Vol. 6. Dai Z, editor. Berlin, Heidelberg: SpringerSeries in Biomaterials Science and Engineering; 2016.

135. Eichwurzel I, Stiel H, Röder B. Photophysical studies of the pheophorbide a dimer. $J$ Photochem Photobiol B. 2000;54:194-200. doi:10.1016/S1011-1344(00)00016-6

136. Tang Q, An Y, Liu D, Liu P, Zhang D. Folate/NIR 797-conjugated albumin magnetic nanospheres: synthesis, characterisation, and in vitro and in vivo targeting evaluation.PLoS One. 2014;9(9):e106483. doi:10.1371/journal. pone.0106483

137. Schuler B, Pannell LK. Specific labeling of polypeptides at amino-terminal cysteine residues using Cy5-benzyl thioester. Bioconjug Chem. 2002;13:1039-1043. doi:10.1021/bc025509t 
138. Chen K, Yap L-P, Park R, et al. A Cy5.5-labeled phage-displayed peptide probe for near-infrared fluorescence imaging of tumor vasculature in living mice. Amino Acids. 2012;42:1329-1337. doi:10.1007/s00726-010-0827-5

139. Harbater O, Efrati M, Gannot I. Quantification of two fluorophores' concentration ratio in a mice model in preparation for a proposed method for early detection of alzheimer's disease. Appl Sci. 2018;8:745. doi:10.3390/app8050745

140. Zhu S, Yung BC, Chandra S, Niu G, Antaris AL, Chen X. Near-Infrared-II (NIR-II) bioimaging via off-peak NIR-I fluorescence emission. Theranostics. 2018;8:4141-4151. doi: $10.7150 /$ thno. 27995

141. ClinicalTrials.gov. Evaluation of IRDye800CW-nimotuzumab in Lung Cancer Surgery - Tabular View. Available from: ClinicalTrials.gov. Accessed February 12, 2021.

142. ClinicalTrials.gov. Phase II Pantiumumab-IRDye800 in Head \& Neck Cancer - Tabular View. Available from: ClinicalTrials.gov. Accessed February 12, 2021.

143. ClinicalTrials.gov. Detection of Early Esophageal Cancer by NIRFME. - Tabular View. Available from: ClinicalTrials.gov. Accessed February 12, 2021.

144. ClinicalTrials.gov. Endoscopic Optical Imaging for Precision Oncology Treatment Applied to Colorectal Tumours (Elios-Coloron-Specimen) - Tabular View. Available from: ClinicalTrials.gov. Accessed February 12, 2021.

145. ClinicalTrials.gov. Detection of PitNET Tissue During TSS Using Bevacizumab-800CW - Tabular View. Available from: ClinicalTrials.gov. Accessed February 12, 2021.

146. ClinicalTrials.gov. Panitumumab-IRDye 800 to Detect Pediatric Neoplasms During Neurosurgical Procedures - Tabular View. Available from: ClinicalTrials.gov. Accessed February 12, 2021.

147. ClinicalTrials.gov. Cetuximab IRDye800 Study as an Optical Imaging Agent to Detect Cancer During Surgical Procedures Tabular View. Available from: ClinicalTrials.gov. Accessed February 12, 2021.

148. ClinicalTrials.gov. VEGF-targeted Fluorescence Near-Infrared (NIR) endoscopy in (pre)malignant esophageal lesions (VICE). Available from: https://clinicaltrials.gov/ct2/show/NCT02129933. Accessed February 12, 2021.

149. ClinicalTrials.gov. Targeted Silica Nanoparticles for Real-Time Image-Guided Intraoperative Mapping of Nodal Metastases Tabular View. Available from: ClinicalTrials.gov. Accessed February 12, 2021.

150. ClinicalTrials.gov. ELUCIDATE: Enabling LUng Cancer IDentification Using folATE Receptor Targeting - Tabular View. Available from: ClinicalTrials.gov. Accessed February 12, 2021.
151. ClinicalTrials.gov. OTL38 for Intra-operative Imaging of Folate Receptor Positive Ovarian Cancer - Tabular View. Available from: ClinicalTrials.gov. Accessed February 12, 2021.

152. ClinicalTrials.gov. OTL38 Injection for Intraoperative Imaging of Folate Receptor Positive Lung Nodules - Tabular View. Available from: ClinicalTrials.gov. Accessed February 12, 2021.

153. ClinicalTrials.gov. Sentinel Lymph Node Biopsy in Breast Cancer Surgery Using ICG - Tabular View. Available from: ClinicalTrials. gov. Accessed February 12, 2021.

154. ClinicalTrials.gov. Sentinel Lymph Node Mapping With Near Infrared Fluorescent Markers - Tabular View. Available from: ClinicalTrials.gov. Accessed February 12, 2021.

155. ClinicalTrials.gov. Application of Surgical Navigation System in Sentinel Lymph Node of Breast Cancer Research - Tabular View. Available from: ClinicalTrials.gov. Accessed February 12, 2021.

156. ClinicalTrials.gov. Intraoperative ICG Fluorescence Imaging for Peritoneal Carcinomatosis Detection - Tabular View. Available from: ClinicalTrials.gov. Accessed February 12, 2021.

157. ClinicalTrials.gov. Evaluation of Indocyanine Green-guided Systematic Pelvic Lymphadenectomy in Endometrial and Cervical Cancer - Tabular View. Available from: ClinicalTrials.gov. Accessed February 12, 2021.

158. ClinicalTrials.gov. Visible Patient ${ }^{\mathrm{TM}}$ With Intravascular Indocyanine Green - Tabular View. Available from: ClinicalTrials.gov. Accessed February 12, 2021.

159. ClinicalTrials.gov. Fluorescent Lymphography-Guided Lymphadenectomy In Laparoscopic Proctectomy - Tabular View. Available from: ClinicalTrials.gov. Accessed February $12,2021$.

160. Netherlands Trial Register.Anon NTR Laparoscopic NearInfrared Fluorescence Imaging of Hepatic Uveal Melanoma Metastases. Available from: https://www.trialregister.nl/trial/ 3700. Accessed February 23, 2021

161. Netherlands Trial Register. Intra-operative identification of colorectal liver metastasis or hepatocellular carcinoma using indocyanin green near infrared fluorescence.. Available from: https:// www.trialregister.nl/trial/2096. Accessed February 23, 2021.

162. ClinicalTrials.gov. A Study to Evaluate ONM-100, an Intraoperative Fluorescence Imaging Agent for the Detection of Cancer - Tabular View. Available from: https://www.clinicaltrials.gov/ct2/show/ NCT03735680. Accessed February 12, 2021.
International Journal of Nanomedicine

\section{Publish your work in this journal}

The International Journal of Nanomedicine is an international, peerreviewed journal focusing on the application of nanotechnology in diagnostics, therapeutics, and drug delivery systems throughout the biomedical field. This journal is indexed on PubMed Central, MedLine, CAS, SciSearch ${ }^{\circledR}$, Current Contents ${ }^{\circledR} /$ Clinical Medicine, $^{-}$
Journal Citation Reports/Science Edition, EMBase, Scopus and the Elsevier Bibliographic databases. The manuscript management system is completely online and includes a very quick and fair peer-review system, which is all easy to use. Visit http://www.dovepress.com/ testimonials.php to read real quotes from published authors. 